LA-7395

\title{
Low Flow Velocity, Fine-Screen Heat Exchangers and Vapor-Cooled Cryogenic Current Leads
}

号

$\frac{7}{\omega}$

$\stackrel{\frac{\pi}{2}}{\frac{2}{5}}$ 
LA.7395

UC. -38

issued: September 1978

\title{
Low Flow Velocity, Fine-Screen \\ Heat Exchangers and Vapor-Cooled \\ Cryogenic Current Leads
}

\author{
W. A. Steyert \\ N. J. Stone*
}

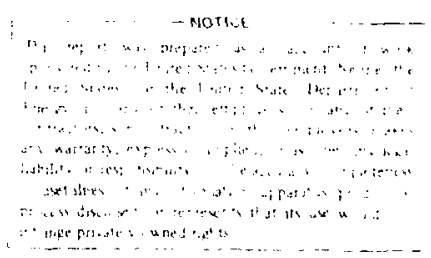

${ }^{*}$ Clarendon Laboratory, Parks Road, Oxford, OXi 3PU, ENGLAND. 
LOW FLOW VELOCITY, FINE-SCREEN HEAT EXCHANGERS

AND VAPOR-COOLED CRYOGENIC CURRENT LEADS

by

W. A. Steyert and W. J. Stone

\begin{abstract}
The design, construction, and testing of three compact, low temperature heat exchangers are reported. A method is given for the construction of a small $\left(\approx 20-\mathrm{cm}^{3}\right.$ volume) exchanger that can handle $6 \mathrm{~g} / \mathrm{s}$ helium flow with low pressure drops $(\Delta P / P=10 \%)$ and adequate heat transfer $\left(N_{1}=3\right)$. The use of screen for simple, vapor-cooled current leads into cryogenic systems is also discussed.
\end{abstract}

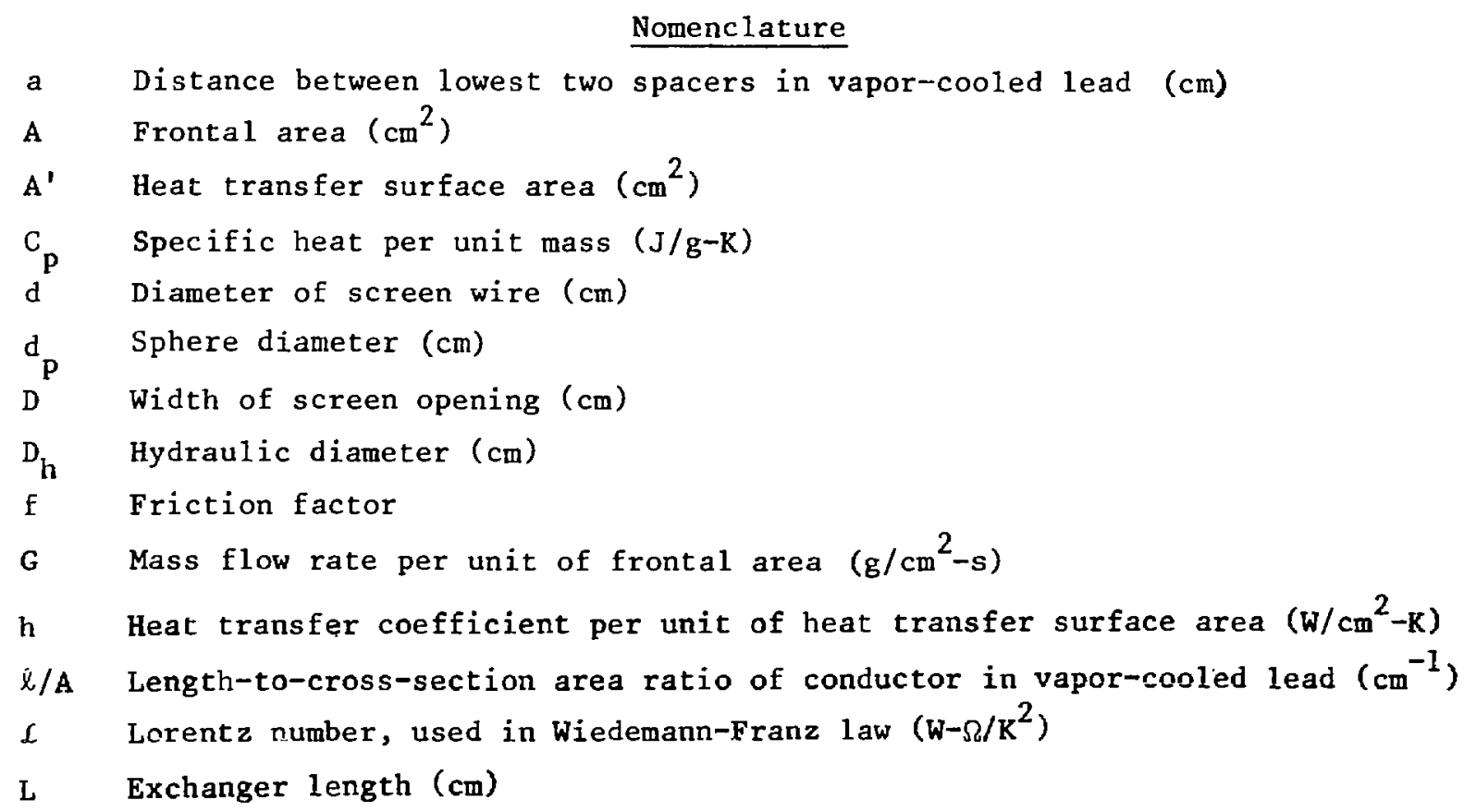




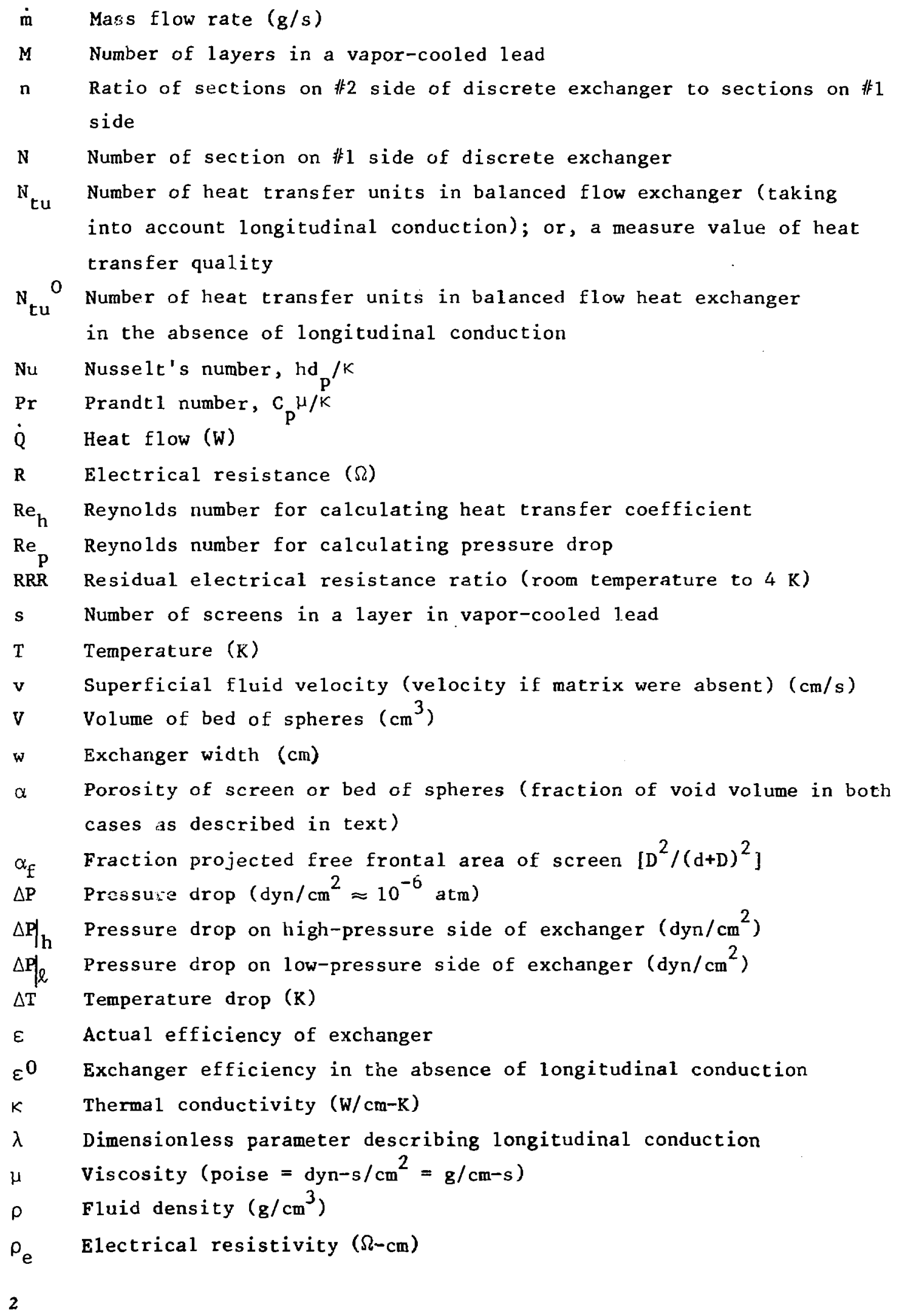




\section{INTRODUCTION}

The design, construction, and testing of three heat exchangers are described. To minimize the need for heat flow through the poorly conducting fluid, particular attention was paid to achieving low fluid flow velocities, large contact surface areas, and small fluid passages.

The merits of such heat exchangers based on these principles are generally recognized. ${ }^{1}$ The objective of this study was to demonstrate that suitably chosen materials and techniques can be used to construnt highly efficient and notably compact units to handle fluid flow rites as high as those normally found in helium liquefiers and other cryogenic apparatus.

In two of the three designs tested, the heat tratacer medium for each fluid flow was 100-mesh (US Std) copper screen.; In the third exchanger, sintered 200- $\mu$ m-dian copper spheres were used in the high-pressure fluid stream. To enhance its thermal conductivity the copper in all exchangers received a high temperature oxygen treatment. ${ }^{2}$ Pressure drops through the exchangers and interflow heat exchange were measured at room temperature and between 4 and $15 \mathrm{~K}$. The quality of the heat exchange performance is discussed in terms of the $\mathrm{N}_{\text {tu }}$ formalism.

The calculation of the heat transfer between fluid and heat exchanger is given in Sec. II, as is the calculaiion of the pressure drop in the fluid as a function of flow path geometry, with specific veiues being given for the mesh and particle beds used in this work. The $\mathrm{N}_{\text {tu }}$ formalism is summarized. The design of the three exchangers is discussed in Sec. III, where specific design aspects and pressure drop and heat transfer calculations are given.

Results of pressure drop measurements at room temperature and in the 5-15 $K$ range and the heat transfer measurements are summarized in Sec. IV. In Sec. V we discuss the application of the three exchangers to a superconducting magnet lead design capable of carrying large currents but stable against local heating and with reduced refrigerant loss. Conclusions are given in Sec. VI.

*Buffalo Wire Works, P.O. Box 129, Buffalo, NY 14240 . 


\section{HEAT EXCHANGER DESIGN}

Pressure Drop and Heat Transfer in Flow Through Screen and Beds of Spheres

Pressure drop in 100-mesh screen. For a rectangular wire mesh, the, dimensionless friction factor ${ }^{4} \mathrm{f}$, relating pressure drop $\Delta P$ to screen dimensions and flow rate, is given by

$$
f-\frac{2 \Delta P \alpha_{f}^{2} \rho}{\left(1-\alpha_{f}^{2}\right) G^{2}} \approx 0.4+\frac{90}{R \in P},
$$

where the Reynolds number for pressure calculation is

$$
\operatorname{Re}_{\mathrm{P}} \equiv \mathrm{GD} /\left(\alpha_{\mathrm{f}} \mu\right)
$$

$\rho$ is the fluid density $\left(\mathrm{g} / \mathrm{cm}^{2}\right) ; \mu$ is the fluid viscosi $\%$ (poise), and $D$ is the projected width of the screen opening. Equation (1) represents one empirical fit to the experimental data to within $\pm 20 \% .4,5$

For 100-mesh screen ( 100 wires per linear inch), the wire diameter $d$ is $0.011 \mathrm{~cm}$ and the diameter of the screen opening $\mathrm{D}$ is $0.014 \mathrm{~cm}$. Therefore, the fraction of projected free frontal area $\alpha_{f}$ is 0.31 and the pressure drop through one layer of 100 -mesh screen is

$$
\Delta P\left(\operatorname{dyn} / \mathrm{cm}^{2}\right)=\left(0.4+\frac{1990 \mu}{G}\right)\left(4.7 \frac{G^{2}}{\rho}\right) .
$$

Heat transfer in 100-mesh screen. For fine screens the heat transfer coefficient $h$ (heat flow per unit heat transfer area $A^{\prime}$ and per unit screengas temperature difference $\Delta T$ ) is so large that accurate measurement is dificult. Published results differ by as much as a factor of 2 (Refs. 5 and 6 ). Taking the mean of these results, we find

$$
h \operatorname{Pr}^{2 / 3} \alpha /\left(G C_{p}\right)=0.63 \operatorname{Re}_{h}^{-0.38},
$$


where

$$
\operatorname{Re}_{h}=(1.27 \mathrm{D}+0.27 \mathrm{~d}) \mathrm{G} /(\alpha \mu) .
$$

Note that the empirical fit for h uses a different definition of the Reynolds number than does the empirical $\mathrm{fit}$ for $\Delta \mathrm{P}$ in (2). $\mathrm{Pr}$ is the PrandtI number, $C_{p} \mu / K . \quad\left(C_{p}\right.$ is the fluid specific heat per unit mass, and $k$ is the fluid thermal conductivity.) Here the porosity $\alpha$ is $1-\pi d / 4(D+d)$. Use of the empirical relation (4) gives the heat transfer coefficient to 100-mesh screen:

$$
h\left(W / \mathrm{cm}^{2}-K\right)=3.6 \mathrm{G}^{0.62} \mathrm{C}_{\mathrm{P}}^{1 / 3} \mathrm{~K}^{2 / 3} / \mu^{0.29}
$$

The heat transfer area $A^{\prime}$ of 100-mesh screen relative to the frontal area $A$ on one side is

$$
\frac{A^{\prime}}{A}=\frac{2 \pi d}{d+D}=2.8
$$

Pressure drop in beds of 200-mesh-diam spheres. The results of Refs. 5 and 7 are similar:

$$
\mathrm{f} \equiv \frac{\Delta \mathrm{P} \mathrm{d}_{\mathrm{p}} \alpha^{3} \mathrm{p}}{\mathrm{LG}^{2}(1-\alpha)} \approx 1.75+\left(150 / \mathrm{Re}_{\mathrm{p}}\right) \text {, }
$$

where $d_{p}$ is the sphere diameter $(0.02 \mathrm{~cm}), \alpha$ is the porosity (volume fraction of voids in the particie bed), and $L$ is the length of bed in the direction of fluid flow. Here

$$
\operatorname{Re}_{P} \equiv d_{P} G /[\mu(1-\alpha)]
$$

Using the measured values of $\alpha=0.39$ and $d_{p}=0.02 \mathrm{~cm}$, we have 


$$
\Delta P\left(\text { dyn } / \mathrm{cm}^{2}\right)=\frac{L G^{2}\left[\left(2.4 \times 10^{6} \mu / G\right)+900\right]}{\rho} .
$$

Heat transfer in beds of 200-um-diam spheres. Considerable uncertainty is involved in estimating the heat transfer in this geometry. Reference 5 has results for small Re; however, measurements are difficult in this range because $h / G C C_{p}$ is so large. Reference 6 provides data only down to $\operatorname{Re}_{h}=25$ for spheres. Other estimates ${ }^{8}$ give Nusselt's number $\mathrm{Nu} \equiv \mathrm{hd} / \mathrm{k}=2$ as $\mathrm{G} \rightarrow$ $O$; Nu becomes larger as $G$ gets larger. We take the values from Ref. 5 as the best compromise; for $\operatorname{Re}>40$, Refs. 5 and 6 provide nearly the same re.ults and for $\operatorname{Re}<10$, values in Ref. 6 lie between those in. Ref. 5 and the $\mathrm{Nu}=2$ values.

From Ref. 6,

$$
\frac{\mathrm{h} \alpha}{\mathrm{GC}_{\mathrm{p}}}=0.21 \mathrm{Re}_{\mathrm{h}}^{-0.31} \mathrm{Pr}^{-1}
$$

where

$$
\operatorname{Re}_{h}=D_{h} G /(\mu \alpha)
$$

Here the best value for the hydraulic diameter $D_{h}$ is $2 \alpha d_{p} / 3(1-\alpha)=$ $0.0085 \mathrm{~cm}$. Thus

$$
h(W / c m-K)=1.76 \times G^{0.69} / \mu^{0.69} .
$$

The heat transfer area in a volume $V\left(\mathrm{~cm}^{3}\right)$ of $200-\mu m$-diam spheres is given numerically by

$$
A^{\prime}\left(\mathrm{cm}^{2}\right)=6 \mathrm{~V}(1-\alpha) / d_{p}=183 \mathrm{~V}
$$

Nu Formulation

The calculations and measurements reported here can be interpreted in terms of balanced counterflow heat exchange between two fluids of constant specific heat. After Barron, ${ }^{3}$ the number of heat transfer units $\mathbf{N}_{\text {tu }}{ }^{0}$ in the absence of longitudinal heat conduction through the exchanger is 


$$
\mathrm{N}_{\mathrm{tu}}{ }^{0}=\frac{\dot{\mathrm{Q}} /\left.\Delta \mathrm{T}\right|_{\text {overall }}}{\mathrm{C}_{\mathrm{p}} \dot{\mathrm{m}}}
$$

where $\dot{Q} / \Delta \mathrm{T}$ |overall is the heat flow between the two streams per unit of temperature difference between them, and $\mathrm{hC}_{\mathrm{p}}$ is the capacity rate $(\mathrm{W} / \mathrm{K})$ in each stream. Exchanger performance can be described alternatively by the effectiveness $\varepsilon$.

$$
\epsilon=\frac{\text { actual heat transferred }}{\text { maximum possible heat transfer }}
$$

for balanced flow; even in the presence of longitudinal conduction

$$
\epsilon=\frac{\mathrm{T}_{2}^{i}-\mathrm{T}_{2}{ }^{e}}{\mathrm{~T}_{2}{ }^{i}-\mathrm{T}_{1}{ }^{i}}=\frac{\mathrm{T}_{1}{ }^{e}-\mathrm{T}_{1}{ }^{i}}{\mathrm{~T}_{2}{ }^{i}-\mathrm{T}_{1}{ }^{i}},
$$

where the subscripts refer to fluid 1 and fluid 2 and the superscripts refer to the incoming fluid $i$ and the exiting fluid e. $T$ is temperature.

In the absence of longitudinal conduction for balanced flow ${ }^{3}$ we have

$$
\epsilon^{0}=\frac{N_{t u}^{0}}{1+N_{t u}^{0}} .
$$

Calculation of $N_{t u}$ The first step is to calculate $\dot{Q} / \Delta \mathrm{T}$ and include the thermal impedance between each stream of gas and the metal as well as the impedance of the metal itself. $\mathbb{N}_{t u}{ }^{0}$ for a particular flow rate is then obtained from (15).

Longitudinal conduction clearly reduces the values of $\varepsilon$ and $N_{t u}$ and is taken into account as follows. The dimensionless longitudinal thermal conduction parameter is calculated, where $\dot{\mathrm{Q}} /\left.\Delta \mathrm{T}\right|_{\mathrm{L}}$ is the longitudinal heat flow per 


$$
\lambda=\frac{\dot{\mathrm{Q}} /\left.\Delta \mathrm{T}\right|_{\mathrm{L}}}{\dot{\mathrm{m}} \mathrm{C}_{\mathrm{p}}}
$$

unit of cemperature difference between the exchanger ends $(W / K)$. The results of Bahnke and Howard ${ }^{9}$ can be used to obtain values of $\varepsilon$, given $\mathrm{N}_{\text {tu }} 0$ and $\lambda$. To obtain the final predicted values we then use the inverse of (18) as the definition of $\mathrm{N}_{\text {tu }}$ in the presence of longitudinal conduction:

$$
\mathbf{N}_{\text {tu }}=\frac{\varepsilon}{1-\varepsilon}
$$

Measurement of $N_{t u}$. Equation (17) is used to calculate $E$ from measurements of $\mathrm{T}_{1}{ }^{i}, \mathrm{~T}_{2}{ }^{i}, \mathrm{~T}_{1} \mathrm{e}^{\mathrm{i}}$, and $\mathrm{T}_{2}{ }^{\mathrm{e}}$ in conditions of balanced flow, and (20) is used to calculate $N_{t u}$. Some measurements were made with slightly unbalanced capacity flow rates. In such cases we calculated $\varepsilon$ as defined by Barron ${ }^{3}$ for unbalanced flow. Figure $3-45$ of Ref. 3 then relates the measured values of $N_{t u}$ characteristic of balanced flow to that $\varepsilon$.

\section{EXCHANGER CONSTRUCTION AND DETAILED PERFORMANCE CALCULATIONS}

A. Concentric Heat Exchanger

Construction. Figure 1 is a cutaway drawing of our concentric heat exchanger. The high-pressure gas flows through a copper tube filled with layers of 100-mesh copper screen placed perpendicular to the flow. The low-pressure gas flows through a much larger area of 100-mesh screen. The unit was built by inserting slightly oversize disks into the $0.7-\mathrm{cm}-\mathrm{diam}$ tube; the tube was then heat-treated for $15 \mathrm{~h}$ in $0.026 \mathrm{~Pa}\left(2 \times 10^{-4}\right.$ torr $)$ of air pressure at $900^{\circ} \mathrm{C}$. This treacment should oxidize the impurities in the copper and provide a high residual electric resistivity ratio (RRR) and a correspondingly high thermal conductivity. ${ }^{2}$ At the same time, the copper screen is diffusion-bonded to the copper tube. The measured electrical resistance of the tube and screen was $0.28 \mathrm{~m} \Omega$ at room temperature, with an $R R R$ to $4 \mathrm{~K}$ of 64 (a value surprisingly low for oxygen-treated copper, possibly because the copper tube was so impure). Next, copper screen annuli (16-mm o.d. and 6-mm 


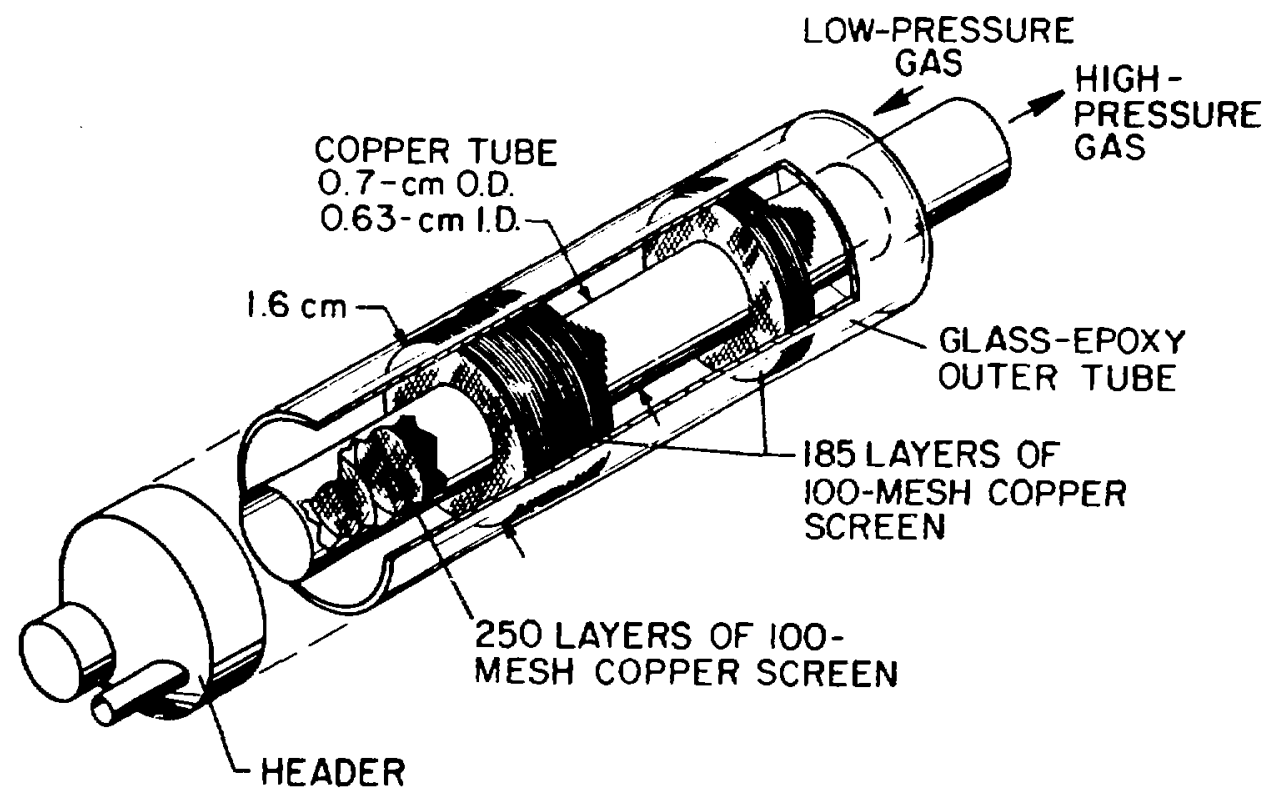

Fig. 1

Concentric-tube heat exchanger. A low-pressure gas header is shown before assembly. Active length of exchanger is $10 \mathrm{~cm}$.

i.d.) were slipped over the $0.7-\mathrm{cm}$ tube. The whole unit was again heattreated in $0.026 \mathrm{~Pa}$ of air at $1010^{\circ} \mathrm{C}$ for $21 \mathrm{~h}$. The final room-temperature resistance was $0.24 \mathrm{~m} \Omega$, with an RRR at $4 \mathrm{~K}$ of 1470 . The increased RRR probably is associated with some diffusion-bonding of the screens to each other as well as with further treatment of the tube at the higher temperature. Metal headers for the low-pressure gas were soldered in place, and a glass cloth-epoxy tube was constructed around the annuli and the headers to contain the low-pressure gas.

Pressure drop $\left.\Delta P\right|_{h}$ on high-pressure side. We will calculate $\left.\Delta \mathrm{P}\right|_{\mathrm{h}}$ for 580 torr of helium at room temperature and for 1 standard atmosphere at low temperature to compare with measurements. We will also predict $\left.\Delta \mathrm{P}\right|_{h}$ for high-pressure helium at low temperatures.

Using ( 3 ) with $G=3.19 \dot{\mathrm{m}}$, we have for 250 layers

$$
\left.\Delta \mathrm{P}\right|_{\mathrm{h}}=1.2 \times 10^{4}(0.4+624 \mu / \dot{\mathrm{m}}) \dot{\mathrm{m}}^{2} / \rho
$$


For room temperature helium*

$$
\left.\Delta \mathrm{P}\right|_{\mathrm{h}}=092 \times 10^{8}\left(0.4 \dot{\mathrm{m}}^{2}+0.12 \dot{\mathrm{m}}\right) .
$$

At $4 \mathrm{~K}$ near 1 atm with a mean temperature of $7.5 \mathrm{~K}$, **

$$
\left.\Delta P\right|_{h}=1.7 \times 10^{6}\left(0.4 \dot{\mathrm{m}}^{2}+0.011 \dot{\mathrm{m}}\right)
$$

At $4 \mathrm{~K}$ and at $i 2$ atm, $\star \star \star$

$$
\left.\Delta \mathrm{P}\right|_{\mathrm{h}}=1.0 \times 10^{5}\left(0.4 \dot{\mathrm{m}}^{2}+0.022 \dot{\mathrm{m}}\right)
$$

$\left.\Delta P\right|_{\ell}$ on Low-pressure side. Again using (3) with $G=0.61 \mathrm{~m}$, we have

$$
\left.\Delta \mathrm{P}\right|_{\ell}=2.5 \times 10^{6}\left(0 . \dot{4} \dot{\mathrm{m}}^{2}+0.63 \dot{\mathrm{m}}\right)
$$

at room temperature and 580 torr, and

$$
\left.\Delta \mathrm{P}\right|_{\ell}=4.7 \times 10^{4}\left(0.4 \dot{\mathrm{m}}^{2}+0.06 \dot{\mathrm{m}}\right)
$$

at $7.5 \mathrm{~K}$ and $1 \mathrm{~atm}$. These values are in dyn $/ \mathrm{cm}^{2}\left(\approx 10^{-6} \mathrm{~atm}\right)$. The curves in Figs, 2 and 3 show the pressure drops calculated for this exchanger.

Fluid-metal heat transfer. From Eqs. (6) and (7) and the exchanger parameters given in Fig. 1, we have for the high-pressure side

$$
\left.h^{\prime}\right|_{h}(W / K)=1620 \dot{m}^{0.62} \mathrm{c}_{p}^{1 / 3} \kappa^{2 / 3} / \mu^{0.29}
$$

and for the low-pressure side

$$
\left.\mathrm{hA}\right|_{2}(\mathrm{~W} / \mathrm{K})=2240 \mathrm{~m}^{0.62} \mathrm{c}_{\mathrm{p}}^{1 / 3} \mathrm{~K}^{2 / 3} / \mu^{0.29}
$$

*For ${ }_{3}$ helium near room temperature we take $\mu$ as $194 \mu$ poise and $\rho=1.3 \times 10^{-4}$ $\mathrm{g} / \mathrm{cm}^{3}$ (atmospheric pressure of 580 torr at Los Alamos, New Mexico), $K=1.52 \mathrm{~mW} / \mathrm{cm}-\mathrm{K}$, and $\mathrm{C}_{\mathrm{p}}=5.19 \mathrm{~J} / \mathrm{g}-\mathrm{K}$.

**For helium at a mean temperature of $7.5 \mathrm{~K}$ and at one standard atmosphere we have $\mu=18.5 \mu$ poise, $\rho=0.0069 \mathrm{~g} / \mathrm{cm}^{3}, K=0.145 \mathrm{~mW} / \mathrm{cm}-\mathrm{K}$, and $\mathrm{C}_{\mathrm{p}}=5.6$
$\mathrm{~J} / \mathrm{g}-\mathrm{K}$.

$\star * *$ For helium at $7.5 \mathrm{~K}$ and 12 atm we have $\mu=36 \mu$ poise, $\rho=0.115 \mathrm{~g} / \mathrm{cm}^{3}, \mathrm{~K}$ $=0.28 \mathrm{~mW} / \mathrm{cm}-\mathrm{K}$, and $\mathrm{C}_{\mathrm{p}}=6.2 \mathrm{~J} / \mathrm{g}-\mathrm{K}$. 


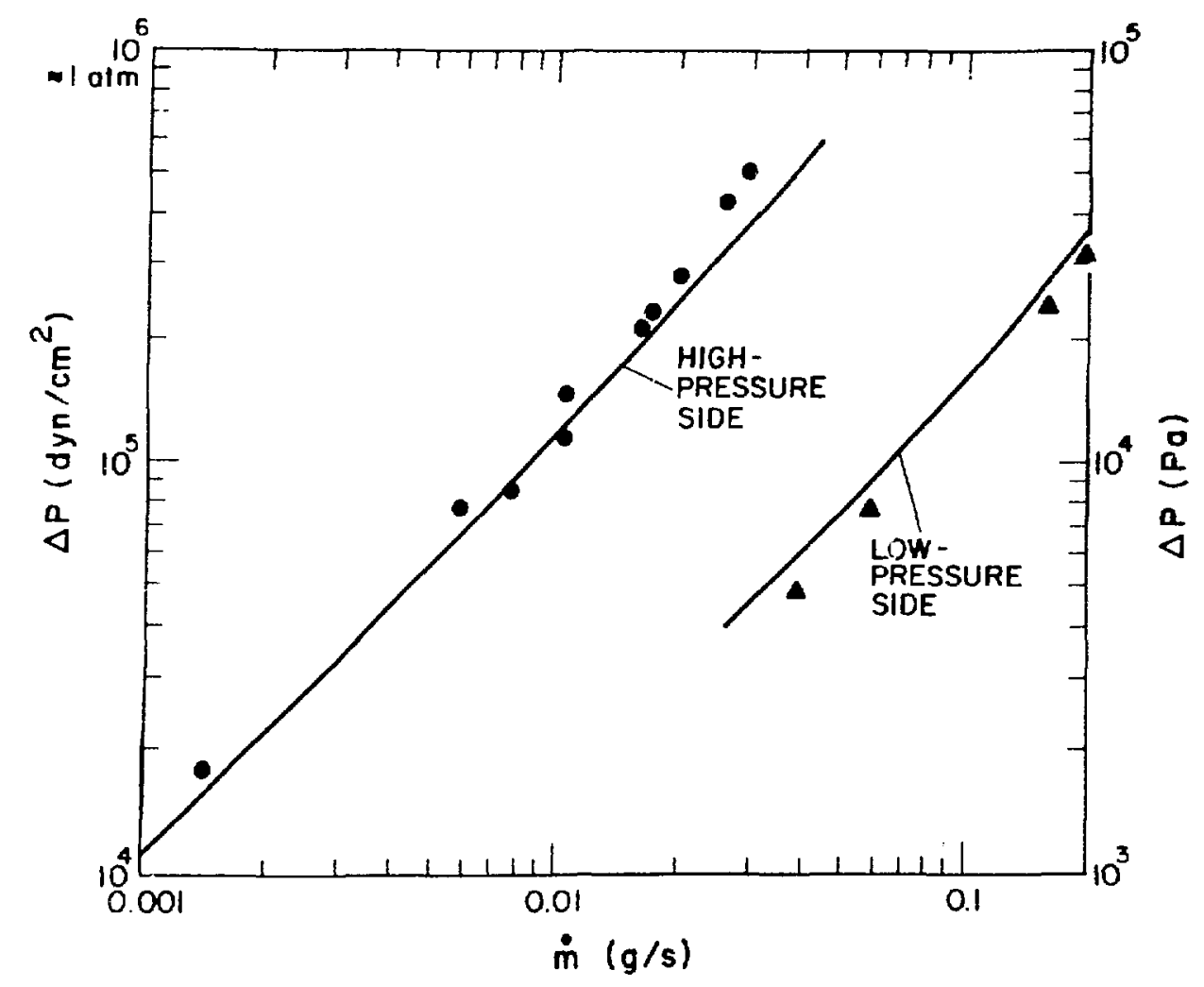

Fig. 2

Pressure drop vs mass flow rate for concentric-tube exchanger. Lines are calculated from Eqs. (22 and (25) for room temperature with mean pressure of 580 torr (local atmospheric pressure) of helium. Points are measured values with outlet pressure of 580 torr.

Transverse heat flow through the screens. The screen can be considered a cylindrical volume of conductivity $K$ and length $L$ into which heat is deposited uniformly. The outside temperature is held at T. Then

$$
\dot{\mathrm{Q}} / \overline{\Delta \mathrm{T}}=8 \pi K \mathrm{~L},
$$

where $\dot{Q}$ is the total heat being deposited and $\overline{\Delta T}$ is the volume average value of $T(r)-T ; T(r)$ is the temperature of the cylinder at a distance $r$ from its center. 


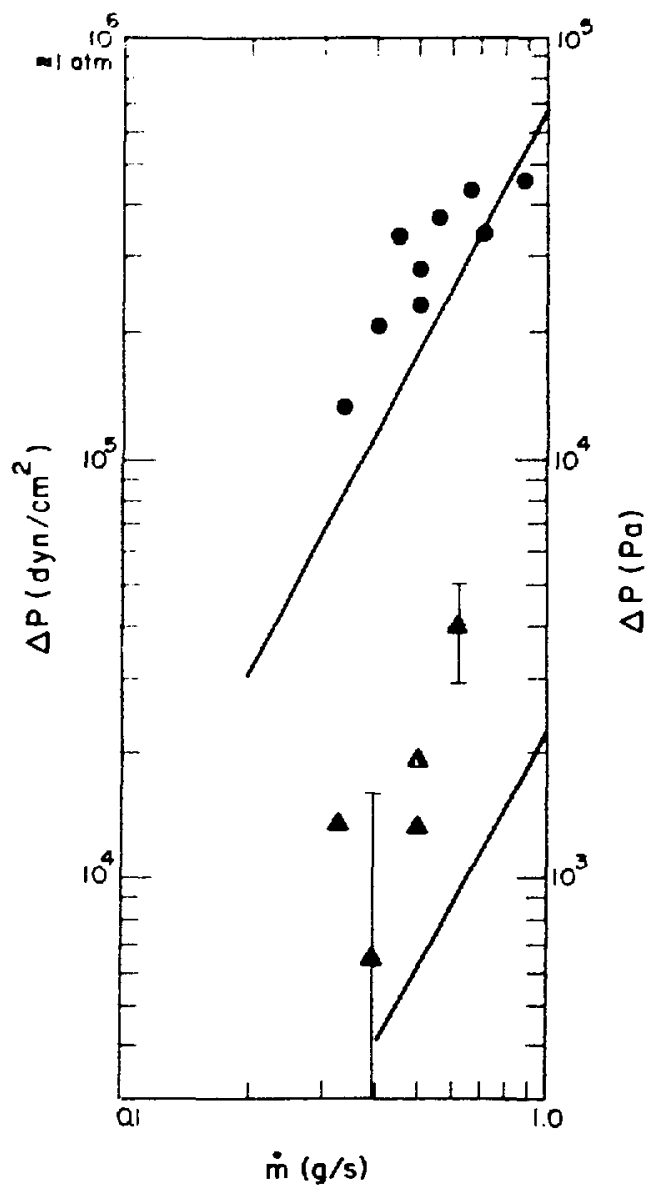

Fig. 3

Pressure drop vs mass flow rate for concentric-tube exchanger. Lines are calculated from Eqs. (23) and (26) for a mean temperature of $\approx 7.5$ at 1 atm. Points are measured values with 580-torr outlet pressure on the low-pressure side (triangles) and slightly above 580-torr outlet pressure on the high-pressure side (circles).

In the high-pressure side we are dealing with 250 layers of screen heated uniformly by the flowing gas. The volume of copper is given by

$$
V=\frac{\pi}{4} \times(0.63)^{2} \times 250 \times 1 / 2 \times \frac{\pi}{4} \times \frac{4 d^{2}(d+D)}{(d+D)^{2}} .
$$


Equating (30) to $r(0.63)^{2} \mathrm{~L} / 4$, where $L$ is the effective length of the screen, gives $L=1.9 \mathrm{~cm}$.

At room temperature we take $k=4.1 \mathrm{~W} / \mathrm{cm}-\mathrm{K}$ and $(29)$ becomes $($ in $\mathrm{W} / \mathrm{K}$ )

$$
\dot{\mathrm{Q}} /\left.\mathrm{LT}\right|_{\mathrm{h}}=196
$$

At low temperatures, we use the Weidemann-Franz law to estimate $K$.

$$
K=\frac{\mathcal{L} T}{\rho_{e}}
$$

where $\mathcal{L}$ is the Lorentz number, approximately $1.9 \times 10^{-8} \mathrm{~W}-\Omega / \mathrm{K}^{2}$ near $7.5 \mathrm{~K}$ for copper. 10 Taking $T=7.5 \mathrm{~K}$ as a mean value, and $\rho_{e}=1.7 \times 10^{-6} / 1470$, we have $k=120 / \mathrm{cm}-K$ or, at low temperatures,

$$
\dot{\mathrm{Q}} /\left.\overline{\Delta \mathrm{T}}\right|_{\mathrm{h}}=5720
$$

In the low-pressure side heat is being deposited uniformly in a thick-walled cylindrical shell at constant $T$ on the inside wall and with no heat loss at the outside wall. Then

$$
\dot{\mathrm{Q}} / \overline{\Delta \mathrm{T}}=\frac{8 \pi \kappa \mathrm{L}\left(D^{2}-1\right)}{4 D^{4}(\ln D)\left(D^{2}-1\right)^{-1}-\left(3 D^{2}-1\right)}
$$

where $D$ is the ratio of the inner to the outer cylinder diameter. With the effective $\mathrm{L}=1.4$ for 185 screen layers, $D=2.3, \dot{\mathrm{Q}} / \overline{\Delta T}=22 \mathrm{~K}$. Thus, with the above values of $K$ at room temperature,

$$
\dot{\mathrm{Q}} /\left.\overline{\Delta \mathrm{T}}\right|_{\ell}=90.2
$$

whereas at low temperatures

$$
\dot{\mathrm{Q}} /\left.\overline{\Delta \mathrm{T}}\right|_{\ell}=2640
$$


Calculation of $N_{t u}{ }^{0}$. $\mathrm{N}_{\text {tu }}{ }^{0}$, which neglects longitudina! conduction, can be calculated from the following approximate relation

$$
\begin{aligned}
\dot{Q} /\left.\Delta T\right|_{\text {overall }} \approx & \left\{\left(\left.i A^{\prime}\right|_{h}\right)^{-1}+\left(\left.h A^{\prime}\right|_{\ell}\right)^{-1}+\left(\dot{Q} /\left.\overline{\Delta T}\right|_{h}\right)^{-1}\right. \\
& \left.+(\dot{Q} / \overline{\Delta T})^{-1}\right\}^{-1}
\end{aligned}
$$

and the definition of $\mathrm{N}_{t u}{ }^{0}=\dot{Q} / \Delta \mathrm{T}$ overall $/ \mathrm{C}_{\mathrm{p}} \dot{\mathrm{m}}$ is calculated by using (27), (28), (31) or (33), and (35) or (36) and using the properties of the fluids given in footnotes here ${ }^{\star \star}$ and on p. 10.

With the Weidemann-Franz law, the dimensionless longitudinal conduction parameter is***

$$
\lambda=\frac{\mathcal{L} \overline{\mathrm{T}} / \mathbf{R}}{\mathrm{C}_{\mathrm{p}} \dot{\mathrm{m}}},
$$

where $R$, the electrical resistance, is $0.24 \mathrm{~m} \Omega$ and $0.24 / 1440 \mathrm{~m} \Omega$ at room temperature and at $4 \mathrm{~K}$, respectively.

$$
\lambda=\frac{2.5 \times 10^{-8} \times 293 / 0.24 \times 10^{-3}}{C_{p} \dot{m}}=\frac{0.030}{C_{p} \dot{m}}
$$

*For water near room temperature we have $\mu=10$ mpoise, $\rho=1.0 \mathrm{~g} / \mathrm{cm}^{3}, \mathrm{~K}=6$ $\mathrm{mW} / \mathrm{cm}-\mathrm{K}$, and $\mathrm{C}_{\mathrm{P}}=4.18 \mathrm{~J} / \mathrm{g}-\mathrm{K}$.

$\star *$ For nitrogen at room temperature we have $\mu=174$ upoise, $\rho=8.3 \times 10^{-4}$ $\mathrm{g} / \mathrm{cm}^{3}, K=0.26 \mathrm{~mW} / \mathrm{cm}-\mathrm{K}$, and $\mathrm{C}_{\mathrm{p}}=1.04 \mathrm{~J} / \mathrm{g}-\mathrm{K}$.

$* * *$ We use a simple extension of the Weidmann-Franz $1 \mathrm{aw}$ [Eq. (32)] to calculate $\dot{Q} /\left.\Delta \mathrm{T}\right|_{\mathrm{L}}$ in $E q .(19) ; \dot{Q} /\left.\Delta \mathrm{T}\right|_{\mathrm{L}}=\mathrm{KA} / \mathrm{\sim}=\mathcal{L} \mathrm{T} /(\rho \ell / \mathrm{A})=\mathcal{L} \mathrm{T} / \mathrm{R}$, where $\mathrm{R}$ is the longitudinal resistance of the exchanger. 


$$
\lambda=\frac{1.9 \times 10^{-8} \times 7.5 \times 1440 / 0.24 \times 10^{-3}}{C_{p} \dot{m}}=\frac{0.86}{C_{p} \dot{m}}
$$

Using the calculated values of $\lambda$ to correct $\mathrm{N}_{\text {tu }}{ }^{\circ}$, as detailed in Ref. 9 , we calculate the values of $N_{\text {tu }}$ given in Fig. 4 .

B. Sintered-Copper Discrete Screen Exchanger

Construction. Figure 5 is a culsway drawing of our uiscrete screen exchanger. The high-pressure ga'; flows through sintered 200-um-diam spheres.

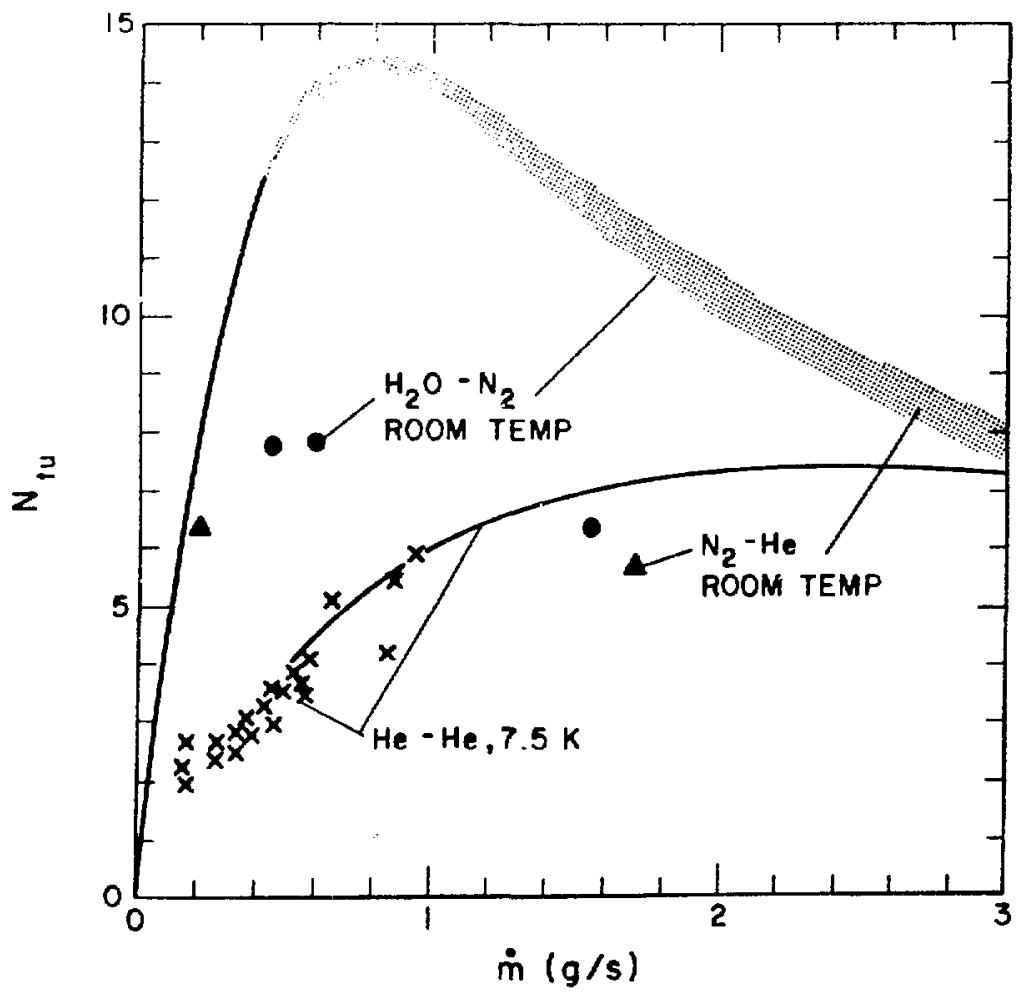

Eig. 4

Number of heat transfer units vs mass flow rate in concentric-tube exchanger for balanced flow. Curves are calculated in text; points are measured values. At room temperature, water in the high-pressure side was measured against nitrogen gas in the low-pressure side as was nitrogen in the high-pressure side vs helium in the low-pressure side. $\dot{m}$ is the nitrogen flow rate for the room-temperature measurements. Incoming fluid temperatures differed by about $40 \mathrm{k}$. $\mathrm{N}$ for helium at a mean temperature of $7.5 \mathrm{~K}$ also was measured and calculated. Incoming fluid temperatures here differed by about $5 \mathrm{~K}$. 


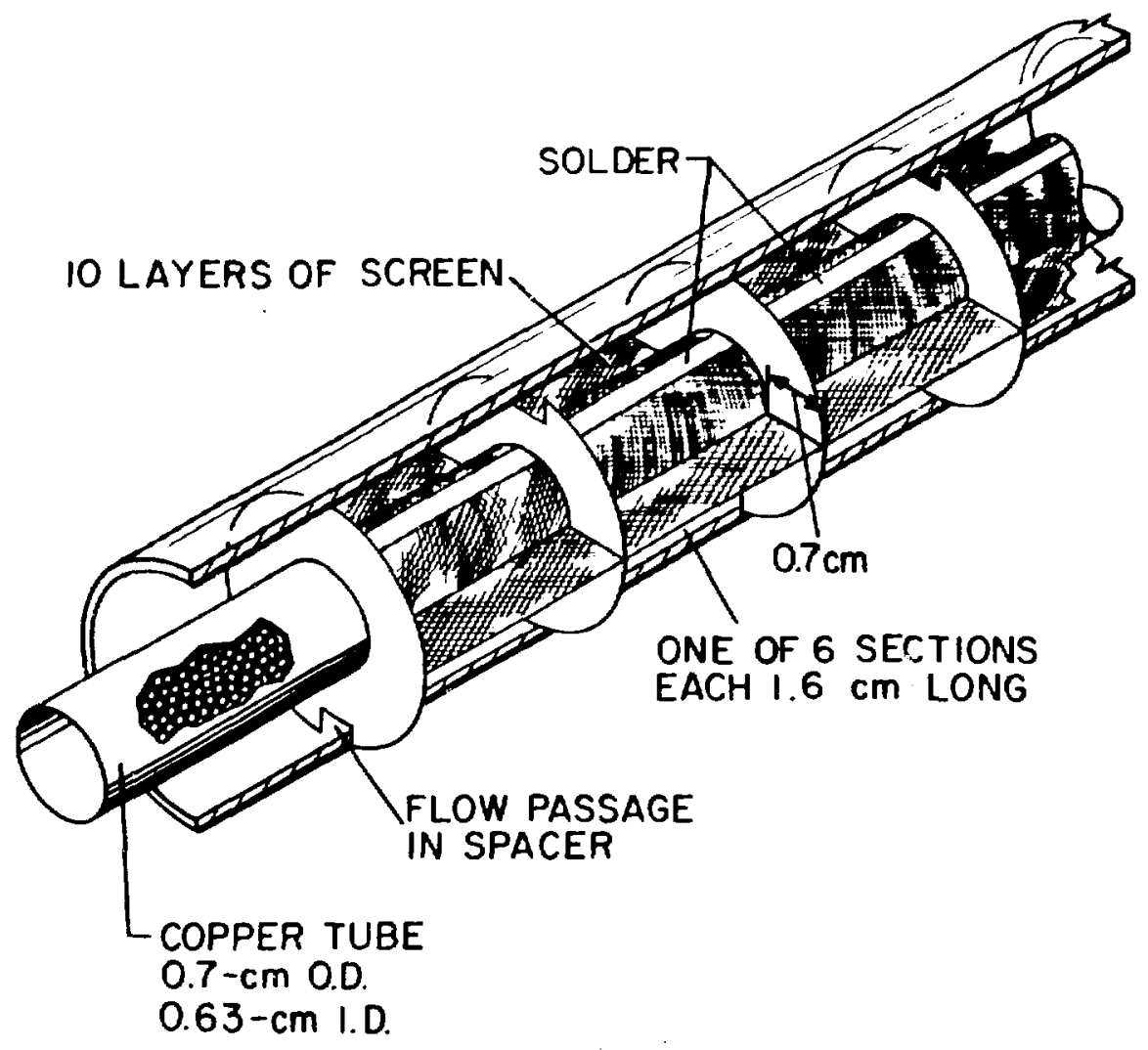

Fig. 5

Sintered-copper discrete heat exchanger. Low-pressure gas headers (Fig. 1) are not shown. Solder is $99.9999 \%$ pure indium, and the outer tube is glass cloth-epoxy. The low-pressure gas weaves up and down through the screen.

The spacers shown in Fig. 5 force the low-pressure gas to weave up and down through copper screens mounted longitudinally within the exchanger. The gas must pass through 6 sections, each $1.6 \mathrm{~cm}$ long and containing 10 layers of screen. Five layers of screen were soldered to each side of the central tube with $99.999 \%$ pure indium. Heauers were installed and the unit was wrapped in glass cloth-epoxy. Before assembly, the tube was treated for $15 \mathrm{~h}$ in 0.026 $\mathrm{Pa}$ of air at $900^{\circ} \mathrm{C}$ to sinter the loosely packed copper spheres (measured filling factor of 0.61 ) and to improve the thermal conductivity at low temperatures. The tube had a $0.24-\mathrm{m} \Omega$ resistance at room temperature, with an $R R R=$ 295. The copper screen was oxygen-treated at $980^{\circ} \mathrm{C}$ for $18 \mathrm{~h}$ in $0.026 \mathrm{~Pa}$ of air pressure. The RRR of the screen was 900. After assembly, the resistance 
of the unit was $0.10 \mathrm{~m} \Omega$ and RRR was 286 (measured slightly above $4 \mathrm{~K}$ so that the indium was a normal conductor).

$\left.\Delta P\right|_{h}$ on high-pressure side. Using Eq. (10), with $G=3.2 \dot{m}$ (from the exchanger dimensions given in Fig. 5) and the gas parameters given in footnotes, p. 10, we have for room-temperature helium at 580 torr the pressure drops (in dyn $/ \mathrm{cm}^{2}$ )

$$
\left.\Delta \mathrm{P}\right|_{\mathrm{ll}}=7.8 \times 10^{5}\left(900 \dot{\mathrm{m}}^{2}+146 \dot{\mathrm{m}}\right)
$$

For $7.5 \mathrm{~K}$ helium at $1 \mathrm{~atm}$,

$$
\Delta \mathrm{P}_{\mathrm{h}}=1.48 \times 10^{4}\left(900 \dot{\mathrm{m}}^{2}+13.9 \dot{\mathrm{m}}\right),
$$

and for $7.5 \mathrm{~K}$ helium at $12 \mathrm{~atm}$,

$$
\left.\Delta \mathrm{P}\right|_{h}=8.9 \times 10^{2}\left(900 \dot{\mathrm{m}}^{2}+22 \dot{\mathrm{m}}\right)
$$

$\left.\Delta P\right|_{\ell}$ on Zow-pressure side. In the low-pressure side, with $G=0.45 \dot{m}$ and using (3) for room-temperature helium at 580 torr, we find the pressure drops (in dyn $/ \mathrm{cm}^{2}$ )

$$
\left.\Delta \mathrm{P}\right|_{\ell}=4.38 \times 10^{5}\left(0.4 \dot{m}^{2}+0.86 \dot{m}\right)
$$

and for $7.5 \mathrm{~K}$ helium at $1 \mathrm{~atm}$,

$$
\left.\Delta \mathrm{P}\right|_{\ell}=8.28 \times 10^{3}\left(0.4 \dot{\mathrm{m}}^{2}+0.082 \dot{\mathrm{m}}\right)
$$

These expressions were used to calculate the curves shown in Figs. 6 and 7 .

Fluid-metal heat transfer. From (13) and (14) and the dimensions given in Fig. 5, we calculate

$$
\left.\mathrm{hA}^{\prime}\right|_{h}=2250 \kappa \dot{\mathrm{m}}^{0.69} / \mu^{0.69}
$$

For the low-pressure side, using (6) and (7), we calculate

$$
\left.\mathrm{hA}^{\prime}\right|_{\ell}=826 \dot{\mathrm{m}}^{0.62} \mathrm{C}_{\mathrm{p}}^{1 / 3} \mathrm{~K}^{2 / 3} / \mu^{0.29}
$$


Later in the calculations we allow for the discrete nature of the low-pressure side.

Transverse heat flow through the eschcinger. We again use (29) for tine high-pressure side, and take $k$ as $1 / 6$ that of the solid metal, on the basis of measurements made at room temperature on another sintered-ccpper sample. With $k=0.68$ at room temperature and $k=3.84$ at $7.5 \mathrm{~K}$, we have at room temperature

$$
\dot{\mathrm{Q}} / \overline{\Delta \mathrm{T}}_{\left.\right|_{\mathrm{h}}}=175
$$

and, at $7.5 \mathrm{~K}$,

$$
\dot{\mathrm{Q}} /\left.\overline{\Delta T}\right|_{\mathrm{h}}=960
$$

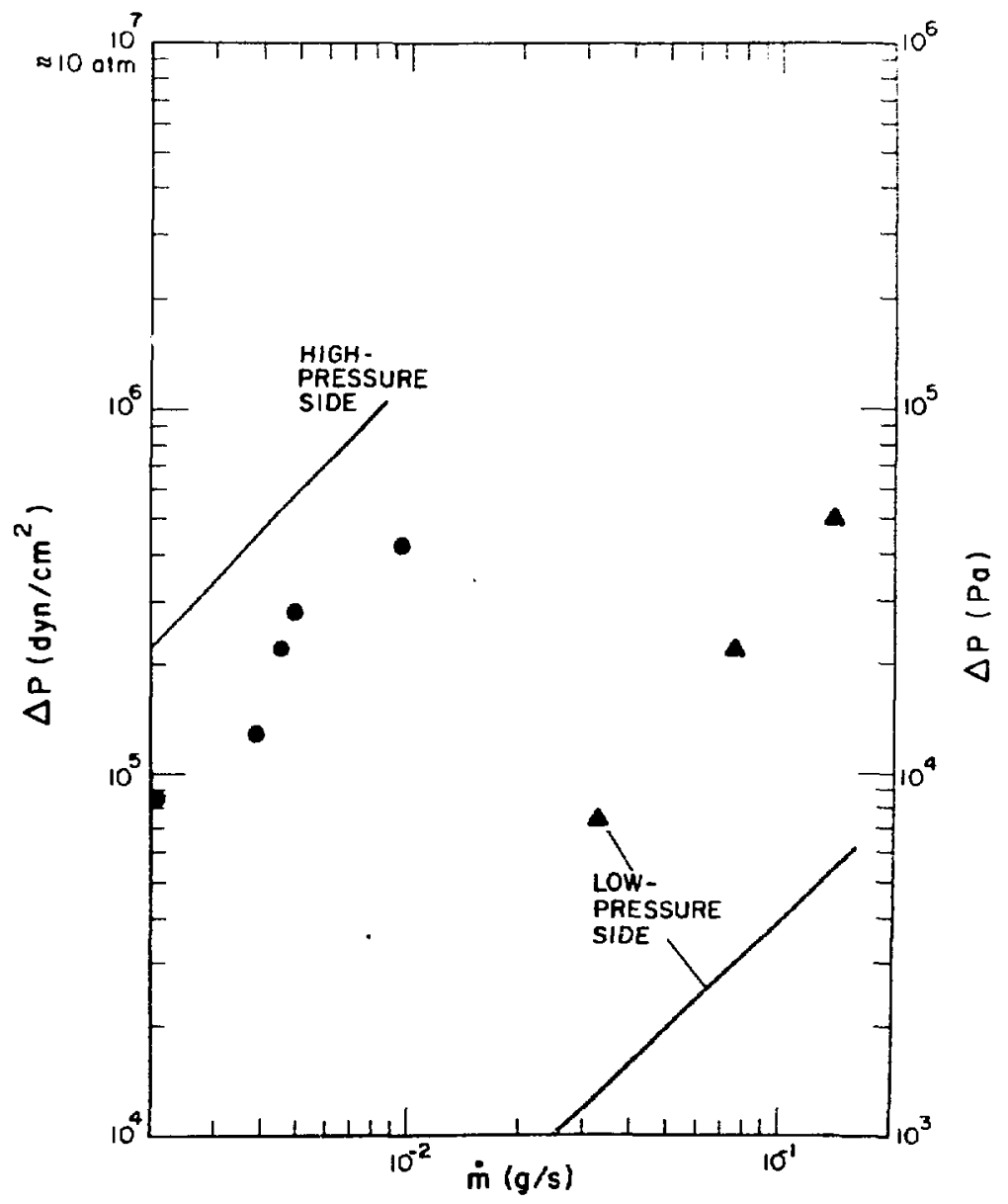

Fig. 6

Pressure drop vs mass flow rate for sintered-copper discrete heat exchanger. Lines are calculated from Eqs. (41) and (44) for helium at 580 torr and at room temperature. Points are measured values with 580-torr outlet pressure. 


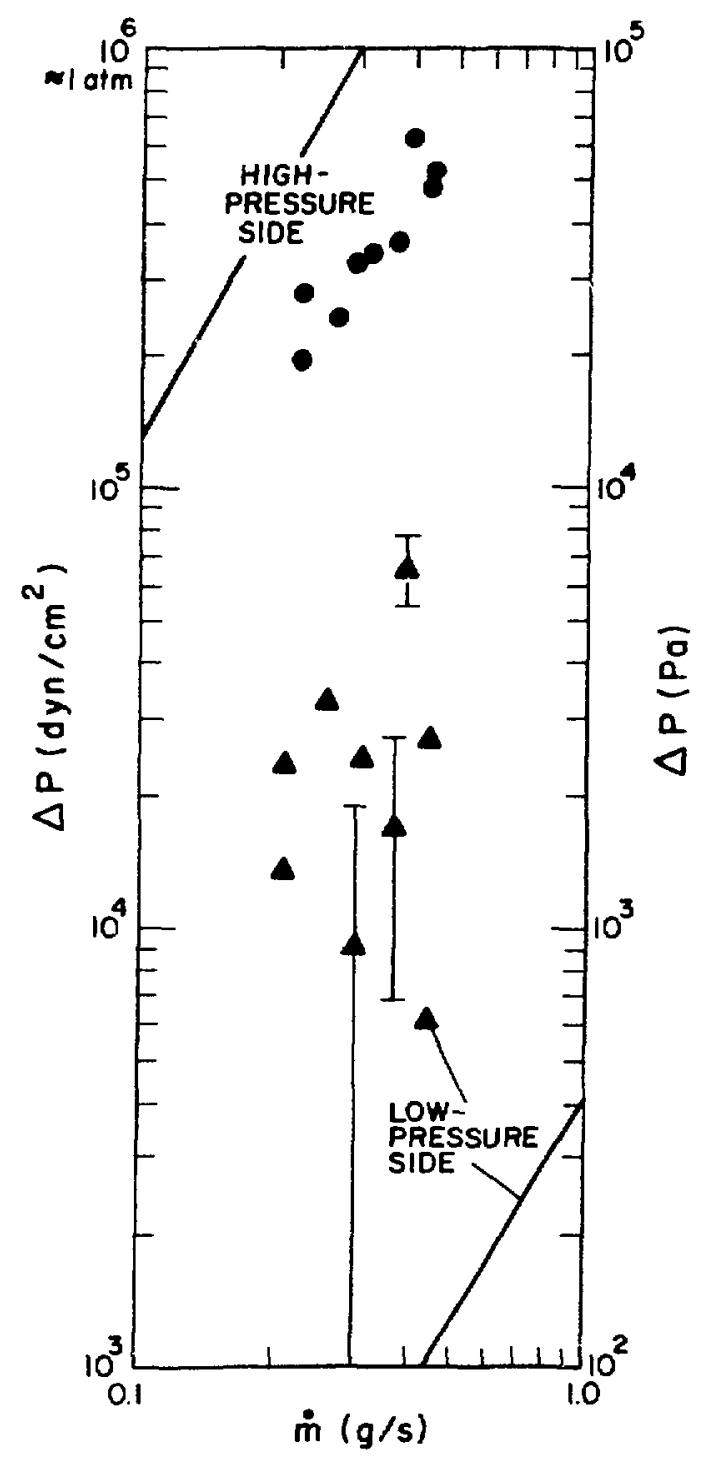

Fig. 7

Pressure drop vs mass flow rate for sinteredcopper discrete heat exchanger. Lines are calulated from Eqs. (42) and (45) for helium at $7.5 \mathrm{~K}$ and $1 \mathrm{~atm}$. Points are measured values with 580-torr outlet pressure on the low-pressure side and slightly above 580 torr on the highpressure side.

In the low-pressure side, for heat uniformly deposited in the screen fins of length $L$ (normal to direction of heat flow), thickness $t$, and width w (along the direction of heat flow), an elementary calculation shows 


$$
\dot{Q} /\left.\overline{L T}\right|_{\%}=3 r \mathrm{t} L / w=3 \kappa \frac{(\pi / 4) d^{2}}{d+D} \mathrm{~L} / \mathrm{w},
$$

where $\overline{\mathrm{AT}}$ is the average $\mathrm{T}(\mathrm{x})-\mathrm{T}$ when one edge is held at $\mathrm{T}$. For the screen, taking $w \approx 0.8$ (heat must travel a little way into the solder joint),

$$
\dot{\mathrm{Q}} / \overline{\Delta \mathrm{T}}_{\left.\right|_{2}}=2.8 \mathrm{r} .
$$

$L=200 \mathrm{~cm}$ because there are fins on two sides of the exchanger and there are 10 layers of screen, each $10 \mathrm{~cm}$ long. At room temperature, $K=4.1 \mathrm{~W} / \mathrm{cm}-\mathrm{K}$ and at $7.5 \mathrm{~K}$. Use of the Weidemann-Franz law and the measured RRR gives $k=72$ $\mathrm{W} / \mathrm{cm}-\mathrm{K}$. Thus at room temperature,

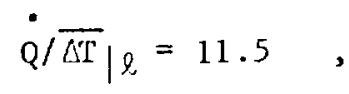

and, at $7.5 \mathrm{~K}$,

$$
\dot{\mathrm{Q} / \overline{\Delta T}} j_{\ell}=202 .
$$

We must also consider the magnitude of $\Delta \mathrm{T}$ across the screen-tube solder joint. We measured the electrical resistance across a number of 10-1ayer screen-solder joints $6 \mathrm{~mm}^{2}$ in area. The average resistance for 10 samples was $8.4 \mu \Omega$ and the RRR was 90. On the average, heat has to travel through 2.5 layers of screen; thus $R=12.6 \mu \Omega$ for a $1-m^{2}$ area. Using the WeidemannFranz law, we expect the conductance at room temperature to be $0.58 \mathrm{~W} / \mathrm{K}-\mathrm{mm}^{2}$, whereas at $7.5 \mathrm{~K}$ the conductance should be $1 \mathrm{~W} / \mathrm{K}-\mathrm{mm}^{2}$. There are rough $1 \mathrm{y}$ $1400 \mathrm{~mm}^{2}$ of solder area, so temperature drops through the solder can be neglected as opposed to the other $\Delta T^{\prime} s$ in the exchanger [for example, Eqs. $(48)-(53)]$.

We use

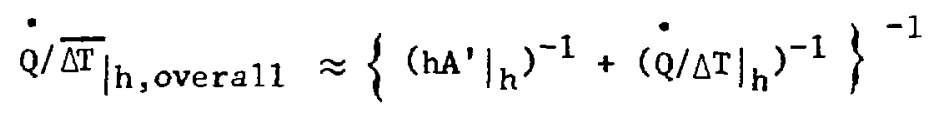

and a similar relation for $\dot{\mathrm{Q}} \sqrt{\Delta \mathrm{T}} \mid \ell^{\prime}$ overal1 from the appropriate equations $(46)-(53)$. 
In the Appendix, the discrete nature of the low-pressure side of the exchanger is taken into account to allow the calculation of $\mathrm{N}_{t u} \mathrm{O}$ by (A-12). With the measured values of $R=0.1 \mathrm{~m}$ at room temperature and $0.1 / 286 \mathrm{~m} \Omega$ at $4 \mathrm{~K}$ and by a calculation similar to that of (39) and (40), we get $\lambda=0.073 / \dot{\mathrm{mC}}_{\mathrm{p}}$ at room temperature and $\lambda=0.408 / \dot{\mathrm{mC}}_{\mathrm{p}}$ at low temperatures. Again, the calculated $\mathrm{N}_{\text {tu }}{ }^{0}$ values were corrected for $\lambda$ as detailed in Ref. 9. The results are given in Fig. 8.

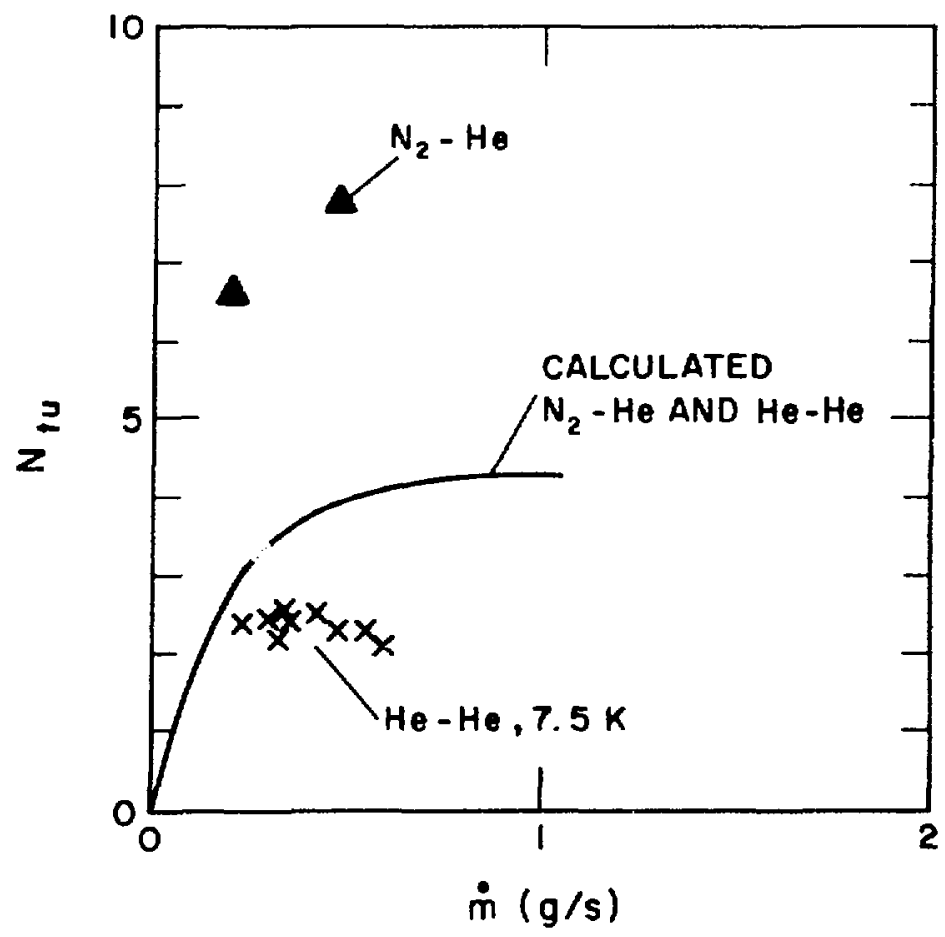

Fig. 8

$\mathrm{N}_{\text {tu }}$ vs mass flow rate in sintered-copper discrete tube exchanger for balanced flow. Curves are calculated in text; points are measured values. At room temperature, nitrogen was in the high-pressure side and helium in the low-pressure side; the temperature of the incoming gases differed by about $40 \mathrm{~K}$. With helium at an average temperature of $7.5 \mathrm{~K}$, the incoming fluid temperatures differed by $5 \mathrm{~K}$. 


\section{Flat Exchanger}

Construction. Figure 9 shows several views of our flat exchanger. The fluid is forced to flow back and forth through the 100-mesh screen. In the high-pressure side the gas makes 24 such excursions at a relatively high $G$. In the low-pressure side the gas executes only 6 such excursions, thereby dropping $G$ by a factor of 4 . The design philosophy of the exchanger was to provide the lowest possible G (mass flow rate per unit of frontal area), hence the lowest $\Delta \mathrm{P}$ in the low-pressure side. The dimensions of the spacers were
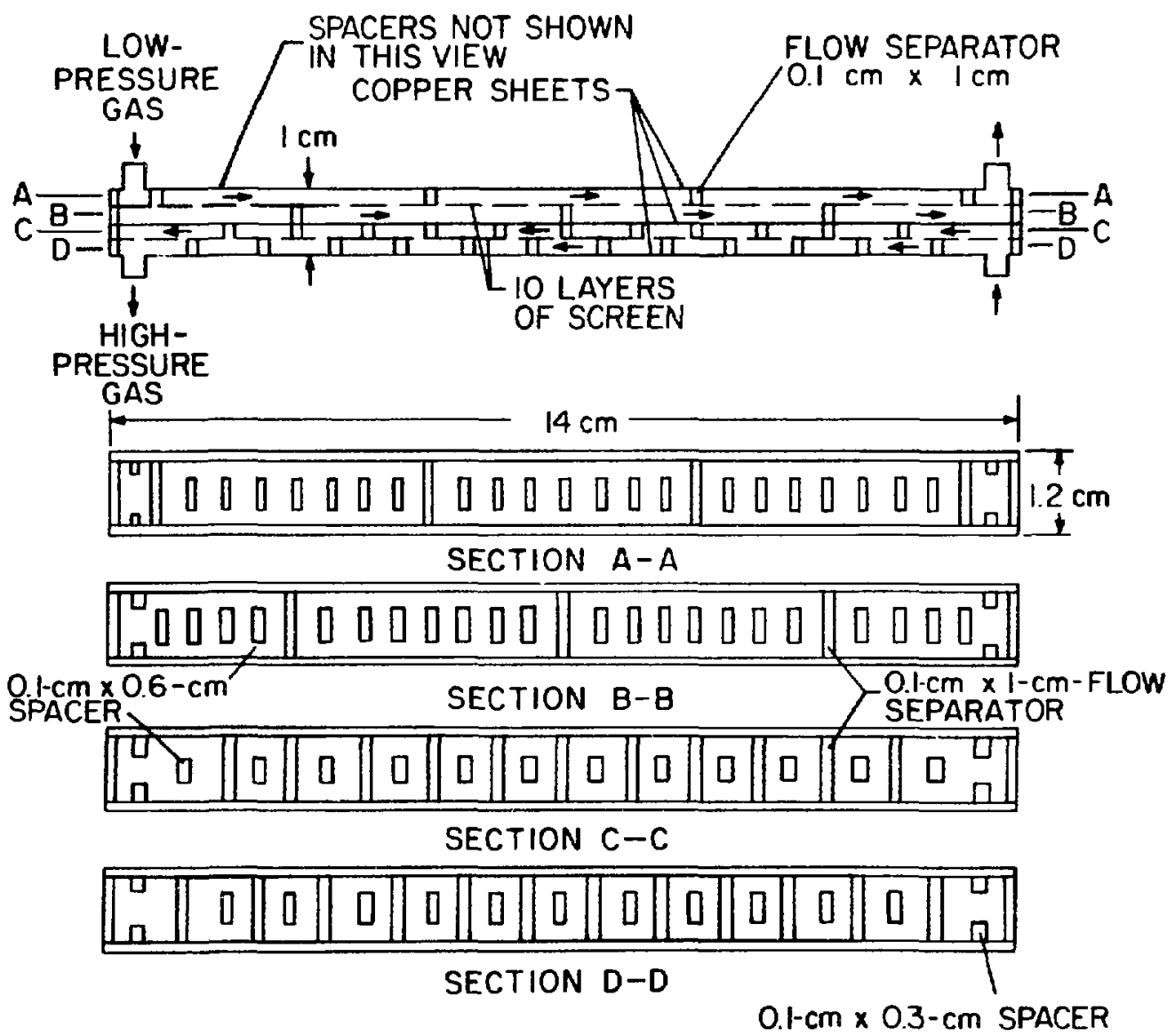

Fig. 9

Flat heat exchanger designed to provide a large area of screen for the gas, thereby keeping $G$ as small as possible. High-pressure layers of screen are physically close to the low-pressure layers so that the conduction path through the overlapping copfer spacers is short. Inlet and outlet ports are not shown in detail. 
chosen to provide a thermal impedance between the high-pressure and low-pressure screens lower than the impedances between the screens and the fluid streams.

The unit was first assembled with glue and placed in a vacuum furnace under a 10-kg weight for $5 \mathrm{~h}$ at $1030^{\circ} \mathrm{C}$. This treatment diffusion-bonded the components together. The unit was then treated in $0.026 \mathrm{~Pa}$ of air at $990^{\circ} \mathrm{C}$ for $21 \mathrm{~h}$ to improve the copper conductivity (the air also helped to remove any glue left after the vacuum treatment). Headers were installed and the sides of the exchanger were vacuum-sealed with lead-tin solder.

The measured electrical resistance of the exchanger at room temperature was $55 \mu \Omega$. Because at low temperatures the superconducting lead-tin solder precludes a meaningful resistance measurement, we take RRk as 500, a value typical of the heat-treated copper used in the exchanger, thus $\mathrm{R} \approx 0.11 \mu \Omega$ at $7.5 \mathrm{~K}$.

Pressure drops. In the high-pressure side, we take as the area of each crossing $\frac{0.85 \mathrm{~cm} \times 1.0 \mathrm{~cm}-0.7 \times 0.2}{2}=0.36 \mathrm{~cm}^{2}$ (allowing $0.05 \mathrm{~cm}$ near each spacer as an ineffective area because of excessive screen compression). We have $\mathrm{G}=2.82 \dot{\mathrm{m}}$ and, using Eq. (3) and the values given in foot:notes, p. 10, and allowing for 240 screen-layer crossings, we calculate the pressure drops $\left(\mathrm{dyn} / \mathrm{cm}^{2}\right.$ ) for room-temperature helium at 580 torr:

$$
\left.\Delta \mathrm{P}\right|_{\mathrm{h}}=6.9 \times 10^{7}\left(0.4 \dot{\mathrm{m}}^{2}+0.14 \dot{\mathrm{m}}\right)
$$

For $7.5 \mathrm{~K}$ helium at $1 \mathrm{~atm}$,

$$
\Delta \mathrm{P}_{\mid \mathrm{h}}=1.3 \times 10^{6}\left(0.4 \dot{\mathrm{m}}^{2}+0.013 \dot{\mathrm{m}}\right)
$$

and, for $7.5 \mathrm{~K}$ helium at $12 \mathrm{~atm}$,

$$
\Delta \mathrm{P}_{\mid h}=7.8 \times 10^{4}\left(0.4 \dot{\mathrm{m}}^{2}+0.025 \dot{\mathrm{m}}\right)
$$

Similarly, in the low-pressure side for room-temperature helium at 580 torc,

$$
\left.\Delta \mathbf{P}\right|_{\ell}=1.0 \times 10^{6}\left(0.4 \dot{\mathrm{m}}^{2}+0.57 \dot{\mathrm{m}}\right)
$$

and, for $7.5 \mathrm{~K}$ helium at $1 \mathrm{~atm}$, 


$$
\Delta \mathrm{P}_{\eta}=1.94 \times 10^{4}\left(0.4 \mathrm{~m}^{2}+0.055 \dot{\mathrm{m}}\right)
$$

Expressions (55) through (59) were used to calculate the curves shown in Figs. 10 and 11.

Pluid-metal heat transfer. From (6) and (7), taking the unobstructed frontal area of the screen to be $86.4 \mathrm{~cm}^{2}$ in the high-pressure side and 87.6 $\mathrm{cm}^{2}$ in the low-pressure side, we have

$$
\mathrm{hA}^{\prime}{ }_{\mathrm{h}}=1660 \dot{\mathrm{m}}^{0.62} \mathrm{C}_{\mathrm{p}}^{1 / 3} \mathrm{r}^{2 / 3} / \mu^{0.29}:
$$

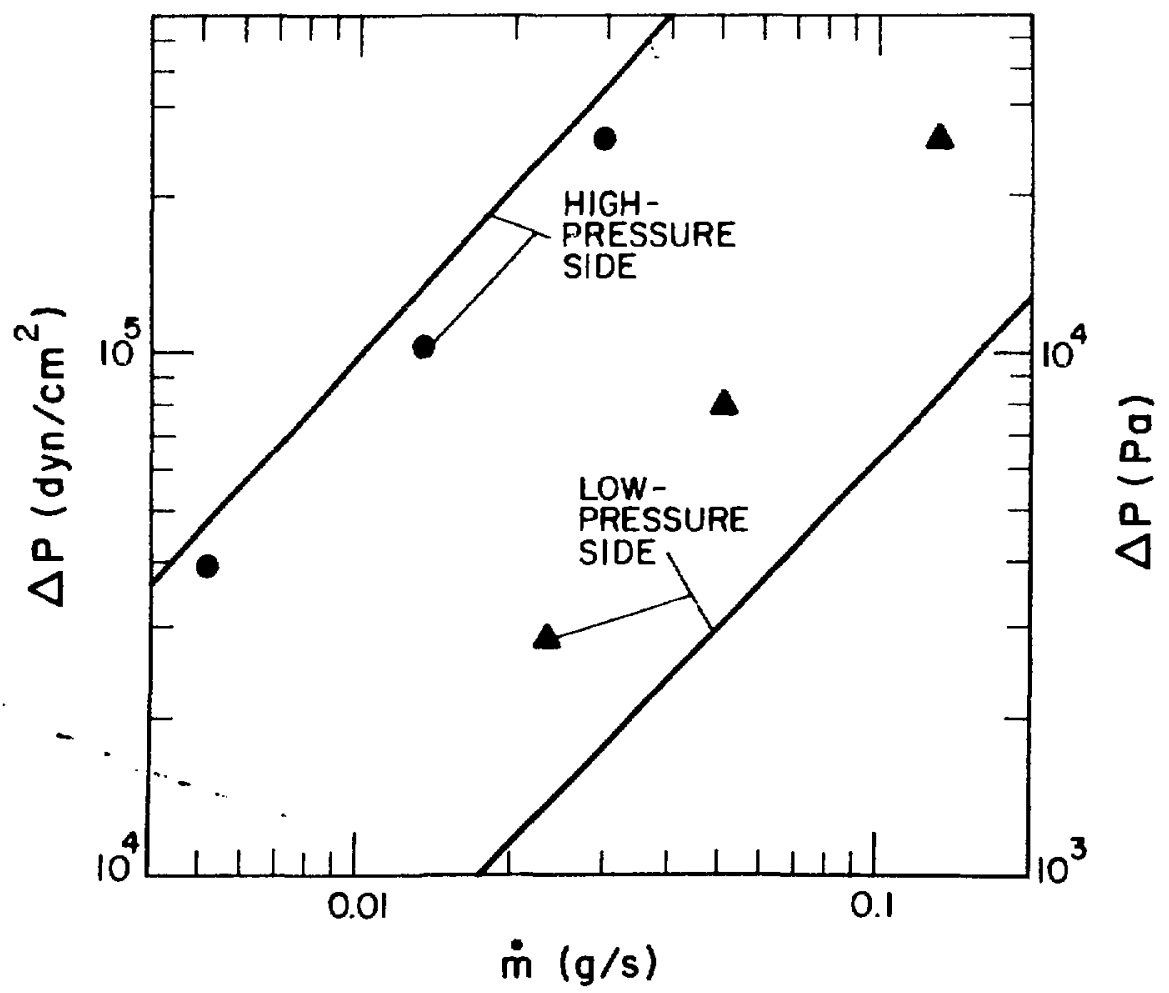

Fig. 10

Pressure drop vs mass flow rate for flat exchanger at room temperature. Lines are calculated from Eqs. (55) and (58). Points are measured values with 580-torr outlet pressure. 


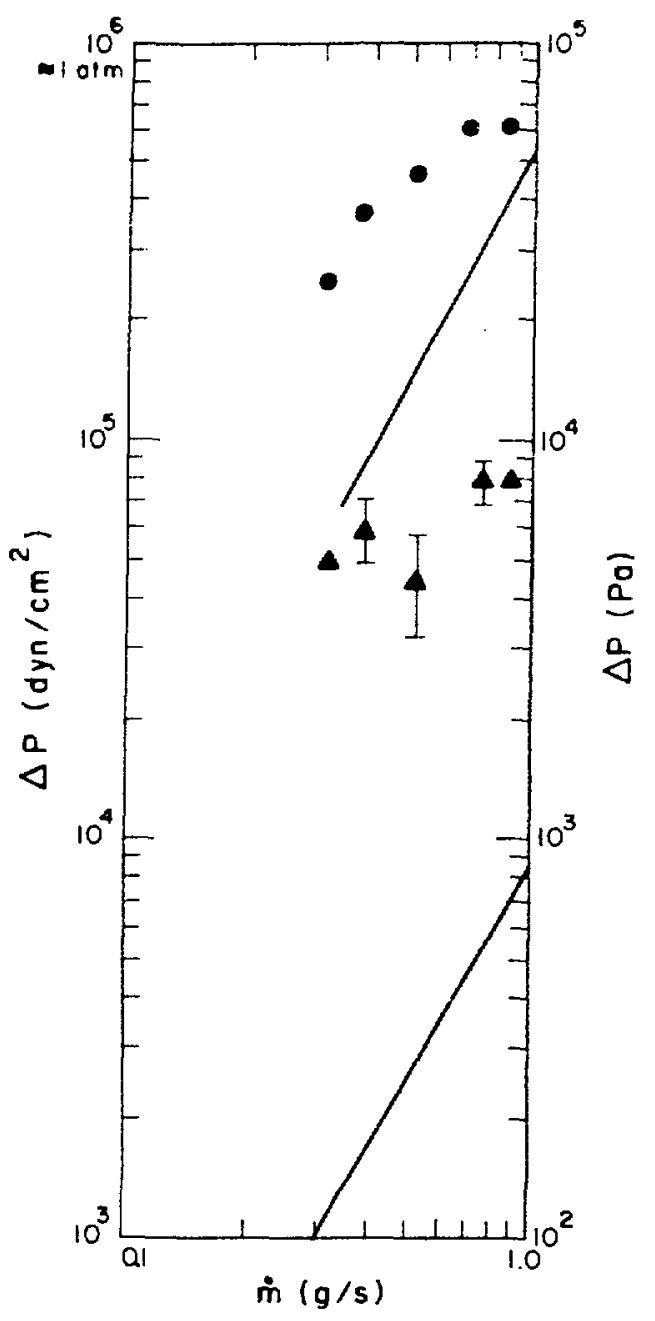

Fig. 11

Pressure drop vs mass flow rate for flat exchanger. Lines are calculated from Eqs. (56) and (59) for $1 \mathrm{~atm}$ of helium at $7.5 \mathrm{~K}$. Points are measured values with 580-torr outlet pressure in low-pressure side (triangles) and slightly above 580 torr in highpressure side (circles).

and

$$
\mathrm{hA}_{\mid \ell}=702 \dot{\mathrm{m}}^{0.62} \mathrm{c}_{\mathrm{p}}^{1 / 3} \kappa^{2 / 3} / \mu^{0.29}
$$


Tronsverse heat flow. In each side of the exchanger, the maximum length of screen that heat must travel to reach a spacer is $0.15 \mathrm{~cm}$. With an analysis similar to that of (50) and (51) we obtain

$$
\dot{\mathrm{Q}} / \overline{\mathrm{AT}}=38 \mathrm{r} .
$$

For heat flow through the metal spacers on each side (the total area of spacers is $3.4 \mathrm{~cm}^{2}$; they are $0.2 \mathrm{~cm}$ thick), we have

$$
\dot{Q} / \overline{\Delta T}=\frac{3.4 K}{0.2}=17 \kappa
$$

We take $k=4.2 \mathrm{~W} / \mathrm{cm}-\mathrm{K}$ at room temperature and, from (32), find $k=42 \mathrm{~W} / \mathrm{cm}-\mathrm{K}$ at $7.5 \mathrm{~K}$.

In addition, we must allow for the impedance of the diffusion bond between the screen and the spacer. Across 10 layers of diffusion-bonded screen into a copper spacer we measure $34.5 \mu \Omega$ for a $1-\mathrm{mm}^{2}$ area at room temperature, with $R R R=150$. If we divide $\Delta T$ by 2 because, on the average, heat flows only halfway across the 10 layers, and use the Weidemann-Franz law again, we have $\dot{Q} / \overline{\Delta T A}=0.42 \mathrm{~W} / \mathrm{K}-\mathrm{mm}^{2}$ at room temperature and $1.2 \mathrm{~W} / \mathrm{K}-\mathrm{mm}^{2}$ at $7.5 \mathrm{~K}$. With $350 \mathrm{~mm}^{2}$ of contact area in both the high- and low-pressure sides,

$$
\dot{Q} / \overline{\Delta T}=147 \mathrm{~W} / \mathrm{K}
$$

at room temperature and

$$
\dot{\mathrm{Q}} / \overline{\Delta \mathrm{T}}=420 \mathrm{~W} / \mathrm{K}
$$

at $7.5 \mathrm{~K}$. Thus the complete heat path through the metal is

$$
\dot{\mathrm{Q}} / \overline{\Delta \mathrm{T}}=36 \mathrm{~W} / \mathrm{K}
$$

at room temperature and

$$
\dot{Q} / \overrightarrow{\Delta T}=227 \mathrm{~W} / \mathrm{K}
$$


at $7.5 \mathrm{~K}$. The sum of reciprocals of (66) or (6?) with (60) and (61) yields $\dot{Q} /\left.\angle T\right|_{\text {averall }}$ for the high- and low-pressure sides. When inserted in (A-11) these values yield values of $\mathrm{N}_{t u}{ }^{0}$ for the exchanger.

We measure $40 \mu \Omega$ at room temperature to get the exchanger's longitudinal resistance. A meaningful $R$ cannot be measured at low temperatures because of the high superconducting transition of the lead-tin solder on the exchanger. We take RRR of 500 as a typical mean value for the oxygen-treated copper. Using the Weidemann-Franz $1 \mathrm{aw}$, we have $\lambda=0.18 / \dot{\mathrm{mC}} \mathrm{p}$ at room temperature and $\lambda=1.8 / \dot{\mathrm{mC}}$ p at $7.5 \mathrm{~K}$. Now $\mathrm{N}_{\text {tu }}$ can be calculated according to Ref. 9 .

A heat exchanger of this design has longitudinal components that contribute to the undesirable longitudinal conductivity but do not contribute to the desirable transverse conducivity. In later versions, these components were gold-plated; subsequent diffusion of the gold into the copper resulted in a roughly 1 at.\% gold-in-copper alloy with $R R R=2.6$.

\section{EXPERIMENTAL RESULTS}

A. Pressure Drop Tests

At room temperature, helium gas at $10 \mathrm{cal}$ atmospheric pressure (580 torr) was passed through each side of the exchanger, and the pressure drop and volume flow rate were recorded -- a simple technique similar to that reported in Ref. 5. The results are shown in Figs. 2, 6, and 10 .

During the low-temperature heat transfer tests, pres? ure drops and volume flow rates were also recorded and are shown in Figs. 3, 7, and 11 . The pressure drops in the low-pressure side in these tests are subject to considerable uncertainty because the pressure gauges were installed such that the lowpressure side $\Delta \mathrm{P}$ was the difference between two large pressures.

Large deviations from expected pressure drops appear in the roomtemperature and low temperature results for the low-pressure side of the sintered tube exchanger (Figs. 6 and 7 ). Destructive disassembly of the exchanger showed that the glass cloth-epoxy covering had sagged between the spacers and had blocked a large fraction of the screen area, thus causing the large pressure drop.

At low temperature there is an apparent partial blockage of the low-pressure side of the flat exchanger (Fig. 11). 


\section{B. lieat Transfer Measurements}

Heat excliange parameters were measured near room temprerature, first with nitrogen gas flowing through the high-pressure side and helium gas through the low-pressure side and then with water in the high-pressure side and nitrogen on the low-pressure side. One fluid was cooled to about $5^{\circ} \mathrm{C}$ with an ice bath; the other was warmed to about $45^{\circ} \mathrm{C}$ with a hot-water bath. The exchanger was insulated from ambient temperature by a fiber glass wrapping. Inlet and outlet fluid temperatures were measured with a $0.03-c n$ wire-diameter copper-constant and with thermocouples in the flowing fluids, and the gas flows were measured with riy test meters.

The low temperature measurements were performed by flowing low temperature helium gas (boiling from a pressurized dewar) through the high-pressure side of the exchanger. The gas was then electrically heated and returned through the low-pressure side of the exchanger, finally venting through a dry test gas meter that measured the gas volume during a given time. Gas temperatures were measured in the flowing gas with calibrated* carbon resistance thermometers. Each temperature was measured with two thermometers (installed in different places) and the results from the two were always consistent. The data were examined to compare the heat lost by the warm gas with the heat gained by the cold gas. In genera1, this energy balance check was correct to better than $10 \%$, showing that heat transfer to the surroundings was small.

In the low temperature measurements the gas flowing through the high-pressure side of the exchanger increased by as much as 400 torr, resulting in a small imbalance in the capacity flow rates of the two gas streams. The imbalance was corrected for by the method shown in Fig. 3-43 of Ref. 3. Thus, we were able to deduce a measure of $\mathrm{N}_{t u}$ characteristic of balanced flow. Results are shown for both temperature regions in Figs. 4, 8, and 12 .

The concentric-tube exchanger (Fig. 4) did not show the expected large value of $\mathrm{N}_{t u}$ at room temperature. We attribute this to leakage of the gas down the length of the exchanger past the edges of the screens, particularly in the low-pressure side, or to the inadequacy of the approximation in (54).

*Calibrations to $\pm 0.02 \mathrm{~K}$ from $4-20 \mathrm{~K}$ were made by $\mathrm{A}$. Migliori. 


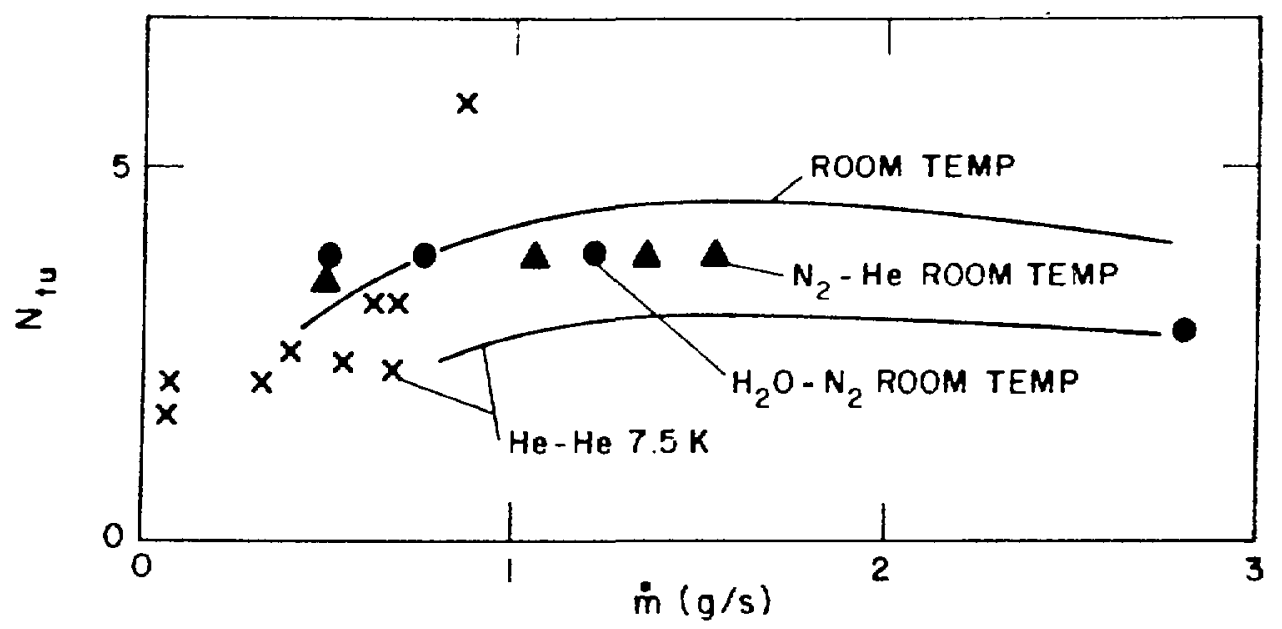

Fig. 12

$N_{t u}$ vs mass flow rate in 1 lat heat exchanger for balanced flow. At room temperature, water was measured against nitrogen on the highpressure side, as was nitrogen ys helium on the low-rreszure side. At room temperature, $\dot{m}$ is the nitrogen gas flow rate; incoming fluid temperatures differed by $40 \mathrm{~K}$. At a mean temperature of $7.5 \mathrm{~K}$, helium was also measured and calculated, im here is the helium flow rate; incoming fluid temperatures differed by about $5 \mathrm{~K}$. The curves are calculated in the text.

The higher-than-expected $N_{t u}$ values of the sintered-tube exchanger at room temperature and the lower-than-expected values at $2 \mathrm{k}$ are not understood. Our calculated $\mathrm{N}_{\text {tu }}$ values may be in error because the longitudinal conduction correction used is applicable strictly to a continuous exchanger and not to the semidiscrete sintered unit.

\section{CRYOGENIC VAPOR-COOLED CURRENT LEADS}

In this section we discuss the application of the discrete fluid flow geometry described above to a vapor-cooled lead entering a cryogenic system. These leads have not yet been built and tested, and in view of the large body of literature on the current-lead problem we do not give a detailed treatment. We demonstrate that leads can be designed to improve on the performance of the best existing designs in terms of loss rate of refrigerant per unit of current, in terms of thermal contact between the leads and the gas, and in terms of pressure drop across the current lead. 
We want to minimize the gas evaporation rate $\dot{m}$ required to self-cool leads of length $\ell$ and cross-sectional area $A$. At the same time we want to minimize the pressure drop as the fluid flows through the lead.

Consider an array of screens as shown in Fig. 13a; 5 100-mesh screens in each layer have 50 spacers to force the flow to interlace the screens. Because of the large temperature difference between the top at $300 \mathrm{~K}$ and the bottom at $4 \mathrm{~K}$, it is best to have the spacers closely spaced at the bottom and widely spaced at the top. At the bottom we want to keep the gas-screen temperature difference $\Delta \mathrm{T}$ small; at the top we can afford a much larger $\Delta T$.

Also, at the bottom of the exchanger a larger mass flow per unit area is possible for a given pressure drop $\Delta \mathrm{P}$ because $\rho$ is larger. Without trying to optimize the system too carefully, we arbitrarily take the spacing between flow spacers to be a at the bottom, increasing linearly to 20 a at the top. The total length $L$ of the exchanger is

$$
\mathrm{L}=525 \mathrm{a}
$$

We take the width of the exchanger as $w$. At the bottom, where $T=4 \mathrm{~K}$, $p=0.015 \mathrm{~g} / \mathrm{cm}^{3}, \mu=13 \times 10^{-6}$ poise, $K=10^{-4} \mathrm{~W} / \mathrm{cm}-\mathrm{K}, C_{p}=9.5 \mathrm{~J} / \mathrm{g}-\mathrm{K}$, and $G=\dot{m} / \mathrm{aw}$, using (3) we have

$$
\Delta \mathrm{P}\left(\mathrm{dyn} / \mathrm{cm}^{2}\right)=313 \mathrm{~s}\left\{0.4\left(\frac{\dot{\mathrm{m}}}{\mathrm{aw}}\right)^{2}+0.026\left(\frac{\dot{\mathrm{m}}}{\mathrm{aw}}\right)\right\}
$$

and, from (6),

$$
h\left(\mathrm{w} / \mathrm{cm}^{2}-\mathrm{k}\right)=0.43(\dot{\mathrm{m}} / \mathrm{aw})^{0.62}=21(\dot{\mathrm{m}} / \mathrm{Lw})^{0.62 ;}
$$

At the top, where $G=\dot{\mathrm{m}} /(20 \mathrm{aw})$, we have

$$
\Delta P\left(\mathrm{dyn} / \mathrm{cm}^{2}\right)=90.5 \mathrm{~s}\left\{0.4\left(\frac{\dot{\mathrm{m}}}{\mathrm{aw}}\right)^{2}+7.7\left(\frac{\dot{\mathrm{m}}}{\mathrm{aw}}\right)\right\}
$$

and

$$
h\left(w / \mathrm{cm}^{2}-k\right)=0.15(\dot{\mathrm{m}} / \mathrm{aw})^{0.62}=7.5(\dot{\mathrm{m}} / \mathrm{Lw})^{0.62}
$$




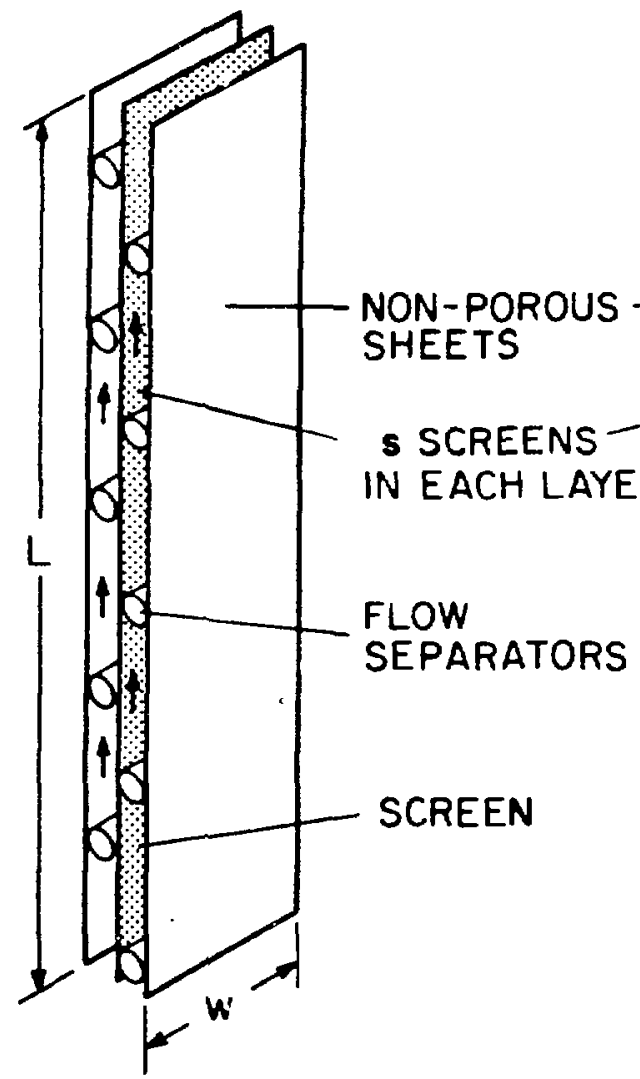

(a)

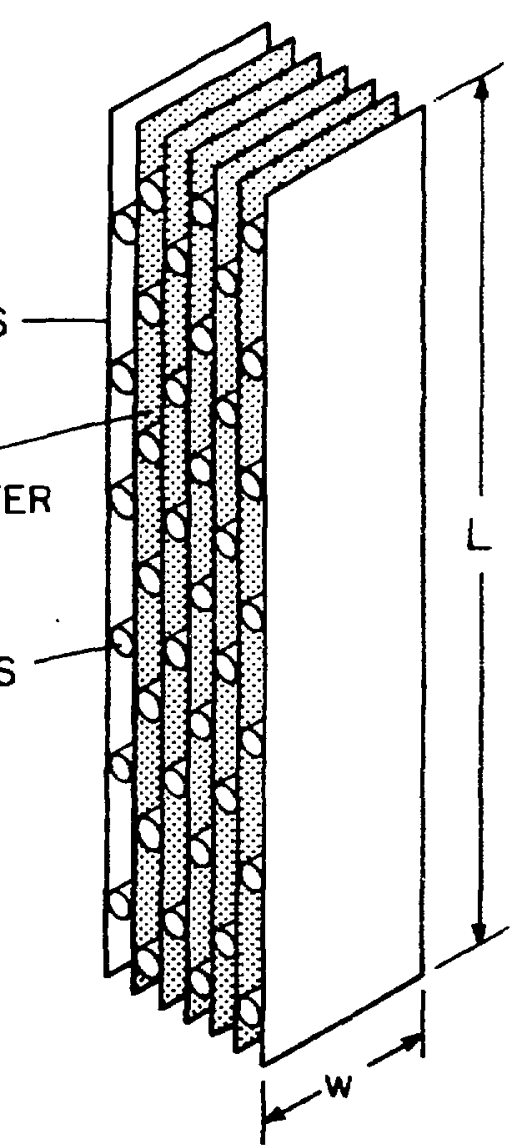

(b)

Fig. 13

Vapor-cooled current lead. (a) $1-\mathrm{kA}$ lead $(\mathrm{s}=10, \mathrm{~L}=20 \mathrm{~cm}$, and $w=2 \mathrm{~cm}$ as in text example).

(b) 25-kA lead ( $s=10$, $L=20$, and $w=5$ ). Five of the 10 layers of screen are shown. For superconducting applications, a horizontal superconducting current lead could be soldered along the width of the screen at the bottom to gather the current. Heavy copper headers vould be needed at the top. To withstand the compressional pinch of the current in 25-kA applications, some kind of mechanical support structure would be needed in addition to the flow separators. Calculations show that spacers a few hundredths of a centimeter thick provide adequate channel widths. Spacers would be more widely separated at the top of the lead than at the bottom. 
The total pressure drop will be roughly 50 times the average of (69) and (71):

$$
\Delta P\left(\mathrm{dyn} / \mathrm{cm}^{2}\right)=\mathrm{s}\left\{1.1 \times 10^{9}\left(\frac{\dot{\mathrm{m}}}{\mathrm{Lw}}\right)+9.3 \times 10^{6}\left(\frac{\dot{\mathrm{m}}}{\mathrm{Lw}}\right)\right\} .
$$

Calculations similar to those of (69) and (71) show that $\hat{\Delta} P$ per screen section near the center of the lead is roughly proportional to the section number, as is required for (73) to be valid. A detailed calculation obviously is needed once a lead temperature profile is decided upon; we took $\mathrm{T}=170 \mathrm{~K}$ near the center of the lead as an overestimate of $T$, hence $\Delta P$. In any event, $\Delta P$ is dominated by the high temperature end of the lead and is not sensitive to these details.

Let us consider what might be reasonable values for Lw and $s$ for a lead to carry $1 \mathrm{ka}$, for example. For copper with an RRR of 50, the lead lengthto-area ratio $\ell / A$ might be $250 \mathrm{~cm}^{-1}$ for a well-designed 1-kA lead: ${ }^{11}$

$$
\ell / A=250=L /\left\{s w \frac{\pi\left(0.011^{2}\right) / 4}{0.025}\right\}=263 \frac{\mathrm{L}}{\mathrm{sw}}
$$

or

$$
\mathrm{L} / \mathrm{sw} \approx 1
$$

Also, $\dot{\mathrm{m}} \approx 0.04 \mathrm{~g} / \mathrm{s}$ for a we11-designed $1-\mathrm{kA}$ lead. 11

Now consider the heat transfer at the top and the bottom of the lead. We will calculate the $\Delta T$ between the hrlium and the screen. Equating the power generation $i^{2} R$ over a fraction of length $F$ of the lead to the heat transfer near the bottom of the lead (where the electrical resistivity of the copper is $\left.3.8 \times 10^{-8} \Omega-\mathrm{cm}\right)$, and taking the $\ell / A$ of the lead to be $250 \mathrm{~cm}^{-1}$ and $\dot{\mathrm{m}}=0.04 \mathrm{~g} / \mathrm{s}$, we find

$$
1000^{2} \times 3.8 \times 10^{-8} \times 250 \mathrm{~F}=21(\dot{\mathrm{m}} / \mathrm{Lw})^{0.62} 2.8 \mathrm{LwsF} \Delta \mathrm{T}
$$


or

$$
\Delta T=1.2 /\left(\mathrm{L}^{0.38} \mathrm{w}^{0.38} \mathrm{~s}\right) \quad .
$$

Similarly, near the top of the exchanger,

$$
\Delta \mathrm{T}=150 /\left(\mathrm{L}^{0.38} \mathrm{w}^{0.38} \mathrm{~s}\right)
$$

If we choose $L=20, s=10$, and $w=2$ [satisfying (75)] we have

$$
\begin{aligned}
& \Delta \mathrm{P}=10^{5} \mathrm{dyn} / \mathrm{cm}^{2}(\approx 0.1 \mathrm{~atm}) \\
& \Delta \mathrm{T}=0.037 \mathrm{~K} \text { at the bottom } \\
& \Delta \mathrm{T}=3.7 \mathrm{~K} \text { at the top }
\end{aligned}
$$

For a larger lead, say, $25 \mathrm{kA}$, we could have $251-\mathrm{kA}$ leads in parallel (m is up by a factor of 25 as we 11 , so $\mathrm{G}, \mathrm{h}$, and $\Delta \mathrm{P}$ are unchanged). Figure $13 \mathrm{~b}$ shows such a lead. It is reasonably compact: $20 \mathrm{~cm} 1 \mathrm{ong}, 5 \mathrm{~cm}$ wide, and 1.5 cm thick.

The $\Delta P$ is much lower than in most leads, and $\Delta T$ is small compared to the usual lead. The main advantage of the lower $\Delta P$ is either a saving in helium compressor power needed to refrigerate the helium leaving the apparatus through the lead or a cooler helium bath when a boiling helium bath is used. The smaller $\Delta \mathrm{T}$ will reduce the lead temperature and the lead resistance. Accordingly, the $i^{2} \mathrm{R}$ losses in the lead are reduced. For an optimum lead, heat conduction into the top is small and the heat leak out the bottom is small compared to $i^{2} R$ (as can be seen by comparing $\dot{Q}=\kappa A(d T / d x)=4$ at the top of the $1-\mathrm{kA}$ lead with $\left.\dot{Q}=\dot{\mathrm{mC}} \mathrm{p}_{\mathrm{p}} \delta \mathrm{T}=61 \mathrm{~W}\right)$. Thus, the decrease in $\mathrm{i}^{2} \mathrm{R}$ is directly reflected in a decrease in $\dot{\mathrm{m}}$ because

$$
\dot{\mathrm{m} C}{ }_{\mathrm{P}} \delta \mathrm{T} \approx \mathrm{i}^{2} \mathrm{R}
$$

In (82) $\delta T$ is the increase in temperature of the gas coming through the leads. As another improvement, $\delta T$ is larger and has better heat exchange, again making m smaller, as indicated by ( 82 ). 
The tight gas-conductor thermal-bonding will make the load more stable against burnout. The effect of thermal contact on stability can be seen if we consider a disturbance that increases the lead temperature by, say, $1 \%$. The $i^{2} R$ will increase by a few percent because of the increase in $R$. The heat transfer from the lead, however, will increase manyfold, causing the lead to cool (if $\dot{m}$ is sufficient to carry the extra local heat).

of course, the small size, simplicity, and lightness of the lead are also important in most applications. These calculations merely outline some of the design considerations, but do show the merits of the heat transfer when screens are used.

\section{CONCLUSIONS}

The use of fine-mesh copper screen allows the construction of a compact heat exchanger having low-pressure drops if the geometry is such that the flow velocity through the screen is small. The large heat transfer coefficients of the fine screen and the resulting compactness of the exchanger permit short conduction paths through the metal, and heat treatment of the copper in 0.026 $\mathrm{Pa}$ of air makes this screen a good conductor. Diffusion-bonded components make exchanger construction rapid and inexpensive. With the use of detailed experimental data, ${ }^{4-8}$ electrical resistance measurements, and the WeidemannFranz law, exchangers can be made with confidence that they will perform as designed (generally with a deviation less than a factor of 2 for properly assembled exchangers).

Table I shows the expected behavior of each side of the three exchangers studied here with a flow rate of $6 \mathrm{~g} / \mathrm{s}$ and with 12 atm in the high-pressure side and 1 atm in the low-pressure side. This might be the final exchanger in a refrigerator; the exchanger would work between roughly 5 and $10 \mathrm{~K}$. Figures 14 and 15 plot expected performance vs flow rate. In all cases, the longitudinal conduction parameter $\lambda$ is small for these high flow rates. Because of the large pressure drops in the high-pressure sides, the sinteredcopper exchanger is inferior to the designs having screens. Small changes in the number of screen layers and in the exchanger dimensions could further reduce $\left.\Delta \mathbf{P}\right|_{h}$ for the screen designs without adversely affecting the heat exchange performance. In the low-pressure side, the concentric exchanger would have some overall advantage, especially if the outside diameter were slightly 


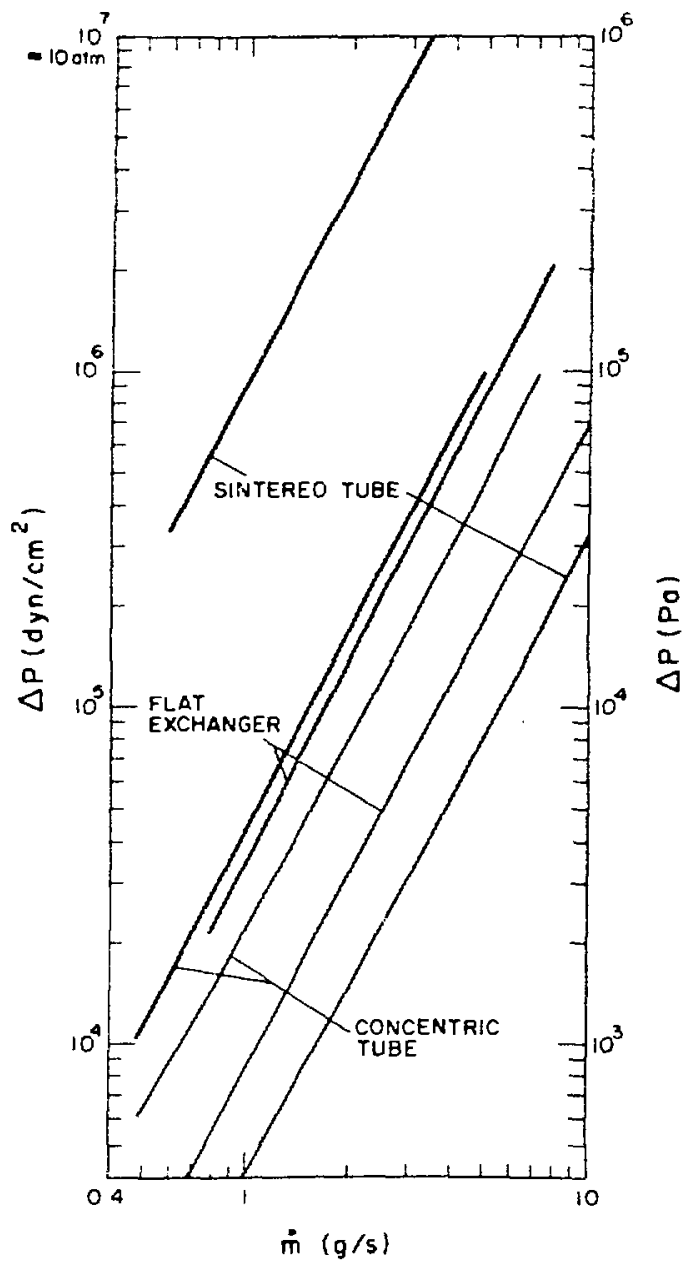

Fig. 14

Calculated pressure drops in the high-pressure (heavy lines) and low-pressure (light lines) sides of each exchanger. The mean temperature is taken as $7.5 \mathrm{~K}$ with 12 atm of pressure in the high-pressure side and 1 atm in the lowpressure side. Curves are taken from Eqs. (24), (26), (43), (45), (57), and (59). 


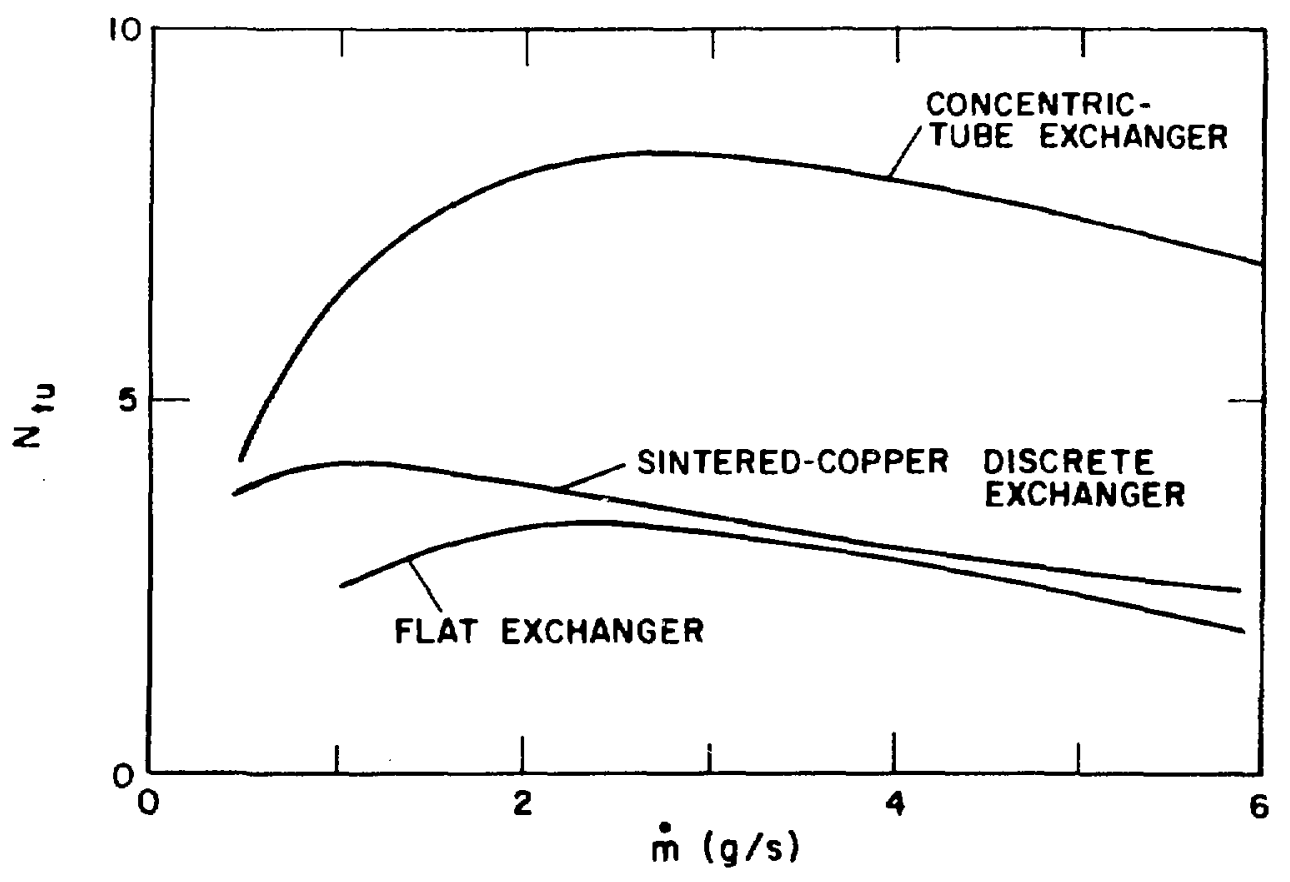

Fig. 15

Expected $N_{\text {tu }}$ vs mass flow rate for the three exchangers described in text. Helium at 12 atm is in the high-pressure side and 1 atm in the low-pressure side, and the mean temperature was $7.5 \mathrm{~K}$.

increased to reduce $\left.\Delta\right|_{\ell}$, but the low-pressure side of all three exchangers would perform wel1.

These results can be extended to the design of microminiature heat exchangers to be used in small Joule-Thomson refrigerators for low temperature instruments (bolometers, SQUID magnetometers, etc.). The load there is $\approx 10$ $\mathrm{mW}$ or less in most cases thus a flow rate $\dot{m}$ of a few milligrams per second of nitrogen, hydrogen, and helium would provide the necessary refrigeration if good heat exchangers were used. The highest temperature stage could be a miniature concentric-tube exchanger with three high-pressure tubes (for the three gases) and divided screen disks for the low-pressure side to provide a separate return path for each gas. With such a small $\dot{m}$, the only design problem is to keep the longitudinal conduction small; because copper could not be used in the high-pressure tubes, an appropriate alloy would be needed. Low-pre'ssure screen layers must not be allowed to touch each other during the diffusion-bonding process. 
TABLE I

EXPECTED PERFORMANCE OF EACH SIDE OF THREE KINDS OF EXCHANGER ${ }^{a}$

\begin{tabular}{l}
\multicolumn{1}{c}{ Exchanger } \\
Concentric-tube \\
Sintered-copper \\
discrete
\end{tabular}

Flat

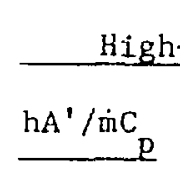

20

68

21

\section{igh-Pressure Side ${ }^{b}$}

$\dot{\mathrm{Q}} /(\Delta \mathrm{T} \dot{\mathrm{m} C}) \quad \Delta \mathrm{P}(\mathrm{atm})$

152

25.6

6.1

1.3

1.5
Low-Pressure Side

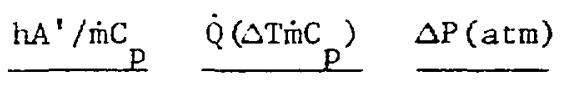

25

78

0.7

8.6

6

0.12

7.3

6.8

0.26

${ }^{a}$ Studied at $6 \mathrm{~g} / \mathrm{s}$ with 12 and 1 atm in high- and low-pressure sides, respectively, and mean temperature of $7.5 \mathrm{~K}$.

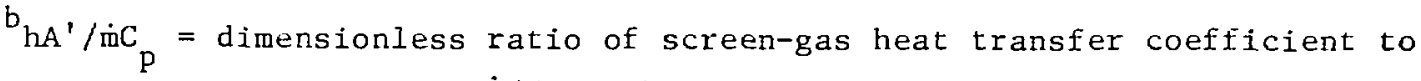
gas capacity flow rate; $\dot{Q} /\left(\Delta \mathrm{T} \dot{m} C_{p}\right)=$ ratio of heat transfer coefficient through the metal to the gas capacity flow rate.

${ }^{C}$ Pressure drop is so large that $6 \mathrm{~g} / \mathrm{s}$ could not be maintained with 12 atm of pressure.

\section{ACKNOWLEDGMENTS}

We are grateful for the expert assistance of $R$. L. Cole in the construction, design, and testing of the exchangers. Discussions with $\mathrm{K}$. D. Williamson were helpful in the initial design stages. We are grateful to S. S. Rosenblum for suggesting the application of this work to vapor-cooled current leads and to $W$. E. Keller for a critical reading of the manuscript.

\section{REFERENCES}

1. W. M. Kays and A. L. London, Compact Heat Exchangers (McGraw Hill, New York, 1964).

2. S. S. Rosenblum, W. A. Steyert, and F. R. Fickett, "A Simple Method for Producing High Conductivity Copper for Low Temperature Applications," Cryogenics 17, 645-647 (1977).

3. R. Barron, Cryogenic Systems (McGraw Hill, New York, 1966). 
4. R. H. Perry and C. H. Chilton, Eds., Chemical Engineers' Handbook, 5th ed. (McGraw Hi11, New York, 1973).

5. W. A. Steyert, "Heat Transfer and Flow Friction in Fine Porous Media," Los Alamos Scientific Laboratory report LA-6912-MS (September 1977).

6. J. E. Coppage and A. L. London, "Heat Transfer and Flow Friction Characteristics of Porous Media," Chem. Eng. Prog. 52, 57-63 (February 1956).

7. E. R. G. Eckert and R. M. Drake, Jr., Heat and Mass Transfer (McGraw Hill, New York, 1959).

8. J. G. Knudsen and D. L. Katz, Fluid Dynamics and Heat Transfer (McGraw Hill, New York, 1958).

9. G. D. Bahnke and C. P. Howard, "Effect of Longitudinal Heat Conduction on Periodic-Flow Heat Exchanger Performance," J. Eng. Power 86, 105-120 (1964).

10. For example, S. J. Wel1s, data sheet DS-156, Hughes Aircraft Co. (1967), available from Defense Documentation Center, Cameron Station, Bldg. 5, 5010 Duke St., Alexandria, VA 22314.

11. G. H. Morgan, "Optimization of Current Leads into a Cryogenic System," Brookhaven National Laboratory report AADD-171 (November 1970).

\section{APPENDIX \\ DISCRETE HEAT EXCHANGERS}

The actual $\mathrm{N}_{\text {tu }}$ value of the discrete exchangers must be related to the $\mathrm{N}_{\text {tu }}$ values of each side of the exchanger, where each side is treated as a continuous exchanger.

\section{N SECTIONS ON EACH SIDE}

First, take $N$ sections on each side of the exchanger (Fig. A-1a). Take the model of each section (Fig. A-1b) where the screen is of such good conductivity that it is isothermal. Fluids enter the section at $T_{1}$ and $T_{2}$ and leave at $\mathrm{T}_{1}{ }^{\prime}$ and $\mathrm{T}_{2}{ }^{\prime}$ after passing through a screen at $\mathrm{T}_{\mathrm{s}}$. Each side of the exchanger has a capacity flow rate $c_{p} \dot{m}$.

$$
\mathrm{T}_{1}{ }^{\prime}-\mathrm{T}_{\mathrm{s}}=\left(\mathrm{T}_{1}-\mathrm{T}_{\mathrm{s}}\right) \exp \left(-\left.\mathrm{hA}^{\prime}\right|_{l} / \dot{\mathrm{m} C} \mathrm{p}_{\mathrm{N}}\right)
$$




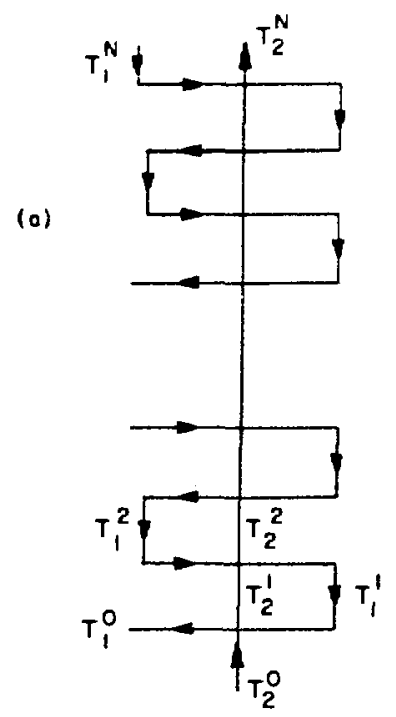

(b)

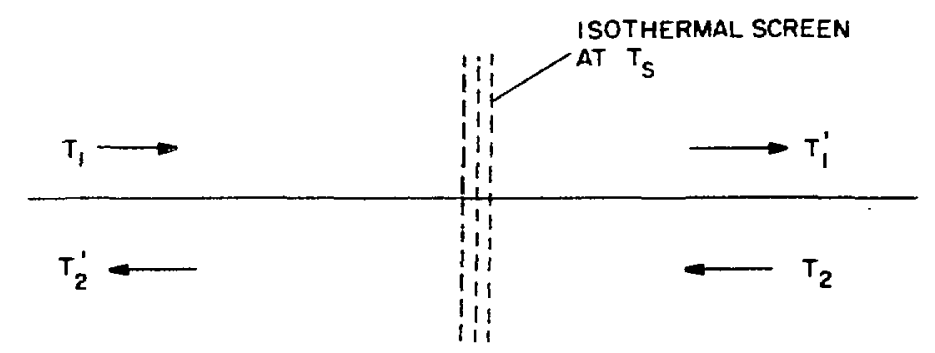

(c)

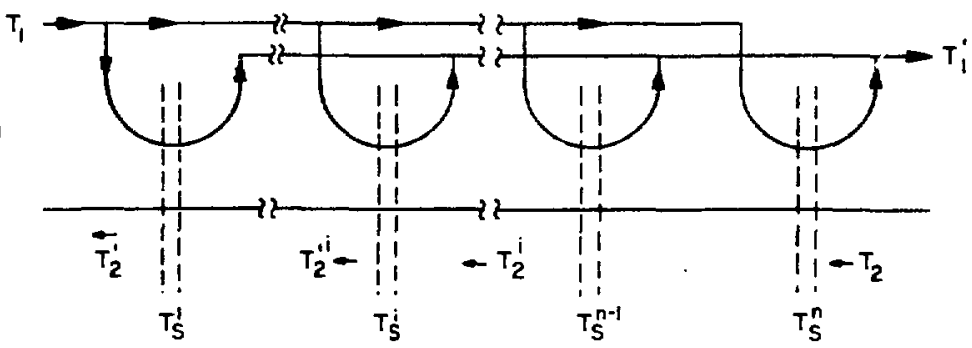

Fig. A-1

Mathematical model of discrete heat exchangers. (a) Model of complete exchanger made up of $\mathrm{N}$ discrete sections, each represented by a fluid-fluid crossing. (b) Detail of fluid-fluid crossing. The screen is considered isothermal (a good heat conductor). (c) More complex model of fluid-fluid crossing. Fluid 1 is split, flows through each of $\mathbf{n}$ subsections, and reunites before leaving each fluid-fluid crossing shown in (a). All of fluid 2 flows successively through each screen subsection. Again, each screen subsection is considered isothermal. 
and

$$
T_{2}{ }^{\prime}-T_{s}=\left(T_{2}-T_{s}\right) \exp \left(-\left.h A\right|_{2} / \dot{m} C_{p} N\right)
$$

$\mathrm{hA}^{\prime} / \mathrm{N}$ is the screen heat transfer for the section. Here $\mathrm{hA}$ ' is approximately the same as $\dot{Q} / \overline{\Delta T}$ loverall of $(54)$ when we take into account $\dot{Q} / \overline{\Delta T}$ in the screen. To simplify the notation, let us define

$$
E_{1} \equiv \exp \left(-h A^{\prime} \mid 1^{/ m} \dot{m}_{\mathbf{p}} \mathbf{H}\right)
$$

and

$$
E_{2} \equiv \exp \left(-h^{\prime}{ }_{\mid 2} / \dot{m} C_{p} N\right)
$$

Equations $(A-1)$ and $(A-1 ')$, combined with the energy conservation law, $\mathrm{T}_{1}{ }^{\prime}-\mathrm{T}_{1}+\mathrm{T}_{2}{ }^{\prime}-\mathrm{T}_{2}=0$, permit solution for $\mathrm{T}_{\mathrm{s}}$. This value of $\mathrm{T}_{\mathrm{s}}$ used in $(A-1)$ and $\left(A-1^{\prime}\right)$ permits the deduction of

$$
E^{\prime}=\frac{T_{2}-T_{2}{ }^{\prime}}{T_{2}-T_{1}}=\frac{T_{1}{ }^{\prime}-T_{1}}{T_{2}-T_{1}}=\frac{\left(1-E_{1}\right)\left(1-E_{2}\right)}{2-E_{1}-E_{2}}
$$

Here $\varepsilon^{\prime}$ is the effectiveness of an exchanger section.

In Fig. $\mathrm{A}-1 \mathrm{a}$, fluids enter the exchanger at $\mathrm{T}_{1}{ }^{\mathrm{N}}$ and $\mathrm{T}_{2}{ }^{0}$ and leave at $\mathrm{T}_{1}{ }^{0}$ and $\mathrm{T}_{2}{ }^{\mathrm{N}}$ after passing through the $\mathrm{N}$ sections, represented in the figure by crossings. The fluid temperatures inside the exchanger $\left(\mathrm{T}_{1}{ }^{1}\right.$, etc.) are defined in Fig. A-1a. Using (A-3) we have

$$
\mathrm{T}_{1}^{1}=\left(\mathrm{T}_{1}^{0}-\varepsilon^{\prime} \mathrm{T}_{2}{ }^{0}\right) /\left(1-\varepsilon^{\prime}\right)
$$

and

$$
\mathrm{T}_{2}{ }^{1}=\left[\varepsilon^{\prime} \mathrm{T}_{1}{ }^{0}+\left(1-2 \varepsilon^{\prime}\right) \mathrm{T}_{2}{ }^{0}\right] /\left(1-\varepsilon^{\prime}\right)
$$


likewise,

$$
\mathrm{T}_{1}{ }^{2}=\left(\mathrm{T}_{1}{ }^{1}-\varepsilon \mathrm{T}_{2}{ }^{1}\right) /\left(1-\varepsilon^{\prime}\right)=\left[\left(1+\varepsilon^{\prime}\right) \mathrm{T}_{1}{ }^{0}-2 \varepsilon^{\prime} \mathrm{T}_{2}{ }^{0}\right] /\left(1-\varepsilon^{\prime}\right)
$$

and

$$
\begin{aligned}
T_{2}{ }^{2}= & {\left[\varepsilon^{\prime} T_{1}{ }^{1}+\left(1-2 \varepsilon^{\prime}\right) T_{2}{ }^{1}\right] /\left(1-\varepsilon^{\prime}\right)=} \\
& {\left[2 \varepsilon^{\prime} T_{1}{ }^{0}+\left(1-3 \varepsilon^{\prime}\right) T_{2}{ }^{0}\right] /\left(1-\varepsilon^{\prime}\right) . }
\end{aligned}
$$

Similarly,

$$
\mathrm{T}_{1}{ }^{3}=\left[\left(1+2 \varepsilon^{\prime}\right) \mathrm{T}_{1}^{0}-3 \varepsilon^{\prime} \mathrm{T}_{2}^{0}\right] /\left(1-\varepsilon^{\prime}\right)
$$

and

$$
\mathrm{T}_{2}{ }^{3}=\left[3 \varepsilon^{\prime} \mathrm{T}_{1}{ }^{0}+\left(1-4 \varepsilon^{\prime}\right) \mathrm{T}_{2}^{0}\right] /\left(1-\varepsilon^{\prime}\right) ;
$$

and finally,

$$
\begin{aligned}
\mathrm{T}_{1}{ }^{\mathrm{N}} & =\left\{\left[1+(\mathrm{N}-1) \epsilon^{\prime}\right] \mathrm{T}_{1}{ }^{0}-\mathrm{N}^{\prime} \mathrm{T}_{2}{ }^{0}\right\} /\left(1-\epsilon^{\prime}\right) \\
& =\mathrm{T}_{1}{ }^{0}-\left[\mathrm{N} \epsilon^{\prime} /\left(1-\epsilon^{\prime}\right)\right]\left(\mathrm{T}_{2}{ }^{0}-\mathrm{T}_{1}{ }^{0}\right) \\
\mathrm{T}_{2}{ }^{\mathrm{N}} & =\left\{\mathrm{N} \epsilon^{\prime} \mathrm{T}_{1}{ }^{0}-\left[1-(\mathrm{N}+1) \epsilon^{\prime}\right] \mathrm{T}_{2}{ }^{0}\right\} /\left(1-\epsilon^{\prime}\right) \\
& +\mathrm{T}_{2}{ }^{0}-\left[\mathrm{N} \epsilon^{\prime} /\left(1-\epsilon^{\prime}\right)\right]\left(\mathrm{T}_{2}{ }^{0}-\mathrm{T}_{1}{ }^{0}\right) .
\end{aligned}
$$


The effectiveness of the complete exchanger is, from (17),

$$
\epsilon=\frac{\mathrm{T}_{1}^{0}-\mathrm{T}_{1}^{\mathrm{N}}}{\mathrm{T}_{2}^{0}-\mathrm{T}_{1}^{\mathrm{N}}}=\frac{N \epsilon^{\prime}}{1-\epsilon^{\prime}+\mathrm{N} \epsilon^{\prime}}
$$

since $\mathrm{N}_{t u}=\epsilon / 1-\epsilon$. Using $(A-8)$ and $(A-7)$ we find

$$
N_{t u}=N \frac{\left(I-E_{1}\right)\left(I-E_{2}\right)}{1-E_{1} E_{2}} \text {. }
$$

N SUBSECTIONS ON ONE SIDE, Nn SUBSECTIONS ON THE OTHER

Figure A-lc shows the model of one section (shown by a fluid crossing in Fig. A-la); however, the section is itself subdivided. This models the flat exchanger. In side 1 (the low-pressure side), $1 / \mathrm{n}^{\text {th }}$ of the fluid at $\mathrm{T}_{1}$ enters each of the $n$ screens. The fluid enters screen $i$ (screen temperature $\mathrm{T}_{s}{ }^{\mathrm{i}}$ ), leaves at some temperature $\mathrm{T}_{1}{ }^{\prime} \mathrm{i}$, and is mixed before it leaves the section. In side 2 all of the fluid goes successively through each screnen, entering at $T_{s}{ }^{\prime} i$ and leaving at $T_{s}{ }^{\prime} i$.

For the entire section, this model results in

$$
\epsilon^{\prime}=\frac{\left(1-E_{1}\right)\left(1-E_{2}\right)}{\left(1-E_{1}\right)+n\left(1-E_{2}\right)},
$$

where in this case

$$
E_{2}=\exp \left(-\left.h A^{\prime}\right|_{2} / \dot{m} C_{p} N n\right)
$$

Again, using $N_{t u}=\varepsilon / 1-\varepsilon$ and $(A-10)$ and $(A-8)$ we find

$$
N_{t u}=N\left\{\left[\frac{\left(1-E_{1}\right)+n\left(1-E_{2}\right)}{E_{2}\left(1-E_{1}\right)+n\left(1-E_{2}\right)}\right]^{n}-1\right\}
$$


DISCRETE EXCHANGER ON ONE SIDE, CONTINUOUS ON THE OTHER

In this case, by letting $n \rightarrow \infty$ in $(A-11)$ we have

$$
N_{t u}=N\left[\exp \left(\frac{\left(1-E_{1}\right) E_{2}}{I-E_{1}+E_{2}}\right)-1\right],
$$

where

$$
E_{2}=\left.h^{\prime}\right|_{2} / \dot{m} C_{p}^{N}
$$

